Pontifícia UNIVERSIDAde CATÓLICA do RIO dE JANEIRO

A negociação de licenças de fabricação e distribuição entre marcas europeias e fabricantes latino americanos

Guillaume Even Lascelles Layolle

Trabalho de Conclusão de Curso

Centro de clências socials - CCS

DePARTAMENTO de AdMINISTRAÇÃo

Graduação em Administração de Empresas 
Guillaume Even Lascelles Layolle

\section{A negociação de licenças de fabricação e distribuição entre marcas europeias e fabricantes latino americanos}

Trabalho de Conclusão de Curso

Trabalho de Conclusão de Curso, apresentado ao programa de graduação em Administração da PUC - Rio como requisito parcial para a obtenção do titulo de graduação em Administração.

Orientadora: Sylvia Moraes

Rio de Janeiro

Junho 2015. 


\section{Agradecimentos}

A professora orientadora deste estudo, Sylvia Moraes, que com muito profissionalismo sempre se fez disponível para orientações ao longo deste estudo.

Aos três entrevistados neste estudo, Carlos Isaac, Françoise Gauci e Hugo Layolle, que foram fundamentais para os resultados do estudo. 


\section{Resumo}

Layolle, Guillaume Even Lascelles. A negociação de licenças de fabricação e distribuição entre marcas europeias e fabricantes latino americanos. Rio de Janeiro, 2015. 67 páginas. Trabalho de Conclusão de Curso Departamento de Administração. Pontifícia Universidade Católica do Rio de Janeiro.

Este trabalho visa analisar o processo de negociação de licenças de fabricação e distribuição entre grifes europeias e fabricantes latino americanos do ponto de vista da empresa intermediadora desta negociação. O foco do estudo recaiu em técnicas de negociação internacional e licenciamento de marca. A pesquisa utilizou o método do estudo de caso, por meio de entrevistas em profundidade com três empresas, cada uma representando um dos participantes da negociação, a saber: uma empresa intermediadora de negociações de licenças, uma empresa licenciada (fabricante) e uma empresa licenciadora (marca). Os principais resultados encontrados foram o uso da estratégia de colaboração por parte da marca, fabricante e intermediadora como a melhor estratégia para uma licença de sucesso e uma relação duradoura entre as partes. A estratégia de concessão também deve ser usada pelo fabricante em alguns pontos da negociação. Os negociadores da empresa intermediadora das negociações devem ser efetivos e intuitivos, enquanto que os negociadores da marca e do fabricante devem ter um perfil analítico.

Palavras- chave

Negociação, Licenças, Licenciamento, Marca, Intermediadora, Internacionalização, Contrato, Grifes europeias, Fabricantes latino americanos. 


\section{Abstract}

Layolle, Guillaume Even Lascelles. The negotiation of manufacturing and distribution licenses between European brands and Latin America manufacturers. Rio de Janeiro, 2015. 67 pages. Trabalho de Conclusão de Curso - Departamento de Administração. Pontifícia Universidade Católica do Rio de Janeiro.

This paper analyzes, from the point of view of the intermediator, the negotiation process of manufacturing and distribution licenses between European brands and Latin America manufacteurs. The focus of the study is the international negotiation techniques and brand licensing. For research, the case study method was used, though in-depth interview with three companies, each representing one of the trading participants, namely: $\mathrm{Na}$ intermediator enterprise license negotiations, a licensee (manufacturer) and a licensing company (brand). The main results were the use of collaborative strategy by brand, manufacturer and intermediator as the Best strategy for a successful and long term relationship between the parties. The concession strategy should also be used by the manufacturer in some points of negotiation. Negotiators from the intermediary company of the negociation should be effective and intuitive, while the negotiators of the brand and manufacturer must have an analytical profile.

\section{Key-words}

Licensing negotiation, licensing, brand, intermediator, internationalization, contract, European brands, manufacturers Latin Americans. 


\section{Sumário}

1 O tema e o problema de estudo 1

1.1. Introdução ao tema e ao problema do estudo 1

1.2. Objetivo do estudo 2

1.3. Objetivos intermediários do estudo 2

1.4. Delimitação e foco do estudo 2

1.5. Justificativa e relevância do estudo 3

2 Revisão de literatura 5

2.1. Internacionalização 5

2.1.1. Estratégias de internacionalização 6

2.1.2. Fatores que interferem no processo de internacionalização 7

2.1.3. Teorias de internacionalização 8

2.1.3.1. Teoria da Firma - Custo de transação 8

2.1.3.2. Teoria da Firma - Visão baseada em recursos 9

2.1.3.3. Teoria da organização industrial 10

2.1.4. Licenciamento da marca 10

2.1.4.1. As vantagens do licenciamento 11

2.1.4.2. As implicações do licenciamento 11

2.1.4.3. O setor de licenças no Brasil 12

2.2. Negociação 13

2.2.1. A pré-negociação 14

2.2.2. Tipos de negociação 15

2.2.3. Estratégias de negociação 16

2.2.4. Negociadores 20

2.2.5. A persuasão 21

$\begin{array}{ll}\text { 2.2.6. Relação entre os players } & 21\end{array}$

3 Métodos e procedimentos de coleta e de análise de dados do estudo 23

3.1. Métodos de pesquisa utilizados 23

3.2. Fontes de informação selecionadas para coleta de dados no estudo24 
3.3. Procedimentos e instrumentos de coleta de dados utilizados no estudo

3.4. Formas de tratamento e análise dos dados coletados para o estudo25

3.5. Limitações do estudo

26

4 Resultados

4.1. A Empresa Fashion Licensing

4.1.1. O processo de negociação de licenças

4.2. A aplicação das teorias na prática

4.2.1. A aplicação das teorias pela intermediadora

4.2.2. A aplicação das teorias pelo fabricante

4.2.3. A aplicação das teorias pela marca

4.3. As melhores práticas e estratégias para uma relação de longo prazo35

5 Conclusões e recomendações para novos estudos

\section{Lista de figuras}

Figura 1: Fatores que interferem no processo de internacionalização da empresa (Madeira e Silveira, 2013).

Figura 2: Estratégias de negociação (Thomas, 1992) .................................... 19

Figura 3: Relação cooperação x competição entre os players (Lam, 2014)....... 22 


\section{Lista de Tabelas}

Tabela 1: Dados do setor de licenças brasileiro (ABRAL) .............................. 13

Tabela 2: Negociações corporativas: Simples x Complexas (Watkins 2006)..... 15 


\section{0 tema e o problema de estudo}

Esse capítulo volta-se à apresentação do tema que se pretende desenvolver e à demonstração do problema de estudo.

Assim, apresenta-se o problema que suscitou a proposta de investigação e os respectivos objetivos de pesquisa. $\mathrm{Na}$ sequência, são indicadas as suposições, a relevância e a justificativa do estudo, além da delimitação e do foco do estudo.

\subsection{Introdução ao tema e ao problema do estudo}

A licença de fabricação e distribuição é uma potente alternativa utilizada pelas empresas que buscam expandir seu território de atuação evitando os altos custos de exportação ou abertura de novas fábricas. Esta permite, através de uma parceria marca $x$ fabricante, a entrada da marca em um novo mercado em potencial (RABELO 2007).

Além da marca e do fabricante, muitas negociações de licenças exigem a participação das chamadas empresas intermediadoras. Estas intermediadoras são contratadas pela marca, e agem como agente representante da marca.

No final do século $X X$, quando as grandes grifes mantinham suas tradições, o emprego das empresas intermediadoras sem negociações não era necessário, pois elas contavam com funcionários internos com conhecimento sobre os mercados específicos aos quais eram destinadas suas atividades. No entanto, com o forte aumento de fusões entre organizações, as empresas estiveram em constante reestruturação, o que gerou uma alta rotatividade de pessoal e a perda destes funcionários (FOLHA DE SÃO PAULO, 2000).

A contratação de uma intermediadora é hoje necessária devido a uma série de fatores que se baseiam na falta de conhecimento do novo mercado por parte da marca. Dentre esses motivos, podemos citar: possibilidades de licenciamento, as possíveis opções de mercado, os possíveis parceiros fabricantes, os diferentes meios de distribuição disponíveis, os posicionamentos de preço, os volumes de fabricação alcançáveis, os interessados em receber licenças, a concorrência e o espaço potencial para a marca em cada mercado (LUDERS, 2014). 
Neste estudo, por meio de entrevistas em profundidade, buscaremos entender em detalhes tudo que envolve a negociação destas licenças, especialmente do ponto de vista da empresa responsável por sua intermediação.

O problema de estudo é: Quais estratégias e práticas de negociação sugerem os melhores resultados na relação entre a marca e o fabricante a longo prazo?

\subsection{Objetivo do estudo}

Apresentar as estratégias de negociação, suas implicações e sugerir as melhores práticas a serem adotadas ao longo de uma negociação para se obter o melhor acordo possível para as duas partes: marca e fabricante.

\subsection{Objetivos intermediários do estudo}

Para se alcançar o objetivo final proposto, esse estudo prevê, como objetivos intermediários a serem alcançados:

$\checkmark \quad$ Identificar as estratégias de negociação internacional.

$\checkmark$ Analisar os processos de negociação, licenciamento e internacionalização.

$\checkmark$ Levantar as estratégias de negociação adotadas pelas partes envolvidas nas negociações de licenças.

$\checkmark$ Analisar a atividade do intermediário no processo de negociações de licenças.

$\checkmark$ Identificar os aspectos positivos, negativos e as consequências das diversas estratégias empregadas durante as negociações entre fabricantes latino americanos e marcas europeias.

\subsection{Delimitação e foco do estudo}

Este estudo volta-se mais especificamente para a abordagem do processo de negociação de licenças de fabricação e distribuição entre grifes europeias e fabricantes latino americanos. Desta maneira, não serão consideras empresas e casos de países não pertencentes a estes continentes.

Será estudada a negociação do ponto de vista da marca, do fabricante e do intermediador, onde serão abordados, além do processo de negociação, os processos de internacionalização e licenciamento da marca. 
Serão abordadas três empresas, cada uma representando uma das partes envolvidas nestas negociações, a saber: Intermediadora, Fabricante e Marca. As empresas são respectivamente: A Fashion Licensing, a Vila Romana e a Yves Saint Laurent.

\subsection{Justificativa e relevância do estudo}

Este estudo permite tomar conhecimento de diversas estratégias de negociações internacionais, identificando as mais vantajosas para uma relação de longo prazo.

O estudo explora também a importância de se preparar para uma negociação, afim de obter os melhores resultados e ter boas opções definidas para qualquer rumo que a negociação possa tomar. Além da pré-negociação, passaremos pela relevância dos fatores que aparecem posteriormente à negociação, como a relação entre os players e os resultados financeiros e veremos como chegar aos melhores cenários.

As licenças de fabricação e distribuição são uma incógnita para muitas pessoas, que não sabem como elas funcionam, bem como quais partes estão envolvidas e seus respectivos papeis.

Será investigado também se a abertura de licenças de fabricação e distribuição podem ser uma boa opção de internacionalização frente aos meios comuns que seriam a exportação de produtos ou abertura de novas fábricas.

Para empresas que estão estudando uma possível entrada em um mercado estrangeiro, principalmente empresas de moda, este estudo permite analisar o licenciamento como uma potente alternativa. Não apenas fornecendo uma abertura de opção, o estudo introduz ao leitor uma clara visão do processo de negociação, as estratégias usadas por empresas com expertise em licenciamento de marca e suas implicações ao longo prazo.

Assim como para empresas interessadas em expandir seu território através de licenças, o estudo também é relevante para fabricantes. Ao fornecer uma sólida base de dados, o estudo permite às empresas fabricantes o conhecimento básico necessário para começar a atuar no segmento de licenças.

Outra parte que pode se beneficiar com o conteúdo deste estudo são empresários, de qualquer segmento, que buscam aperfeiçoar suas técnicas de negociação. Ao citar as principais estratégias de negociação introduzidas por Zajdsznajder (1985) e Thomas (1992) e suas consequências na relação com a 
outra parte e no sucesso da licença, o estudo permite ao leitor identificar a melhor estratégia para um determinado fim.

Segundo a ABRAL (Associação Brasileira de Licenciamento), o faturamento de vendas líquidas no Brasil através de licenças foi de 13 bilhões e 200 milhões de reais no ano passado (2014), aquecendo de forma significativa a economia brasileira como um todo. A média de crescimento deste faturamento nos últimos três anos foi de 4 à $6 \%$ por ano, confirmando a relevância de uma pesquisa que envolve esse setor no Brasil. 


\section{Revisão de literatura}

Neste capítulo são apresentados e discutidos aspectos conceituais e estudos relacionados ao tema e estudo em investigação e que servirão de base para a análise realizada.

Esta seção está dividida em duas partes. A primeira parte consiste nos conceitos, implicações e teorias de internacionalização de empresas na visão de Madeira \& Silveira (2013) e Loureiro (1990). São introduzidos também os conceitos de licenciamento da marca e suas implicações apresentadas por Rabelo (2007). Esta parte visa proporcionar ao leitor uma maior familiaridade com o tema estudado. A segunda parte aborda os conceitos e teorias de todo o processo de negociação, partindo da pré-negociação, passando pelos tipos de negociação, estratégias de negociação, tipos de negociadores e técnicas de persuasão, até a relação entre os players, nas visões de Martinelli (1998), Watkins (2006), Zajdsznajder (1985), Lam (2014), Thomas (1992) e Reck e Long (1990).

\subsection{Internacionalização}

"A internacionalização de uma empresa se refere a toda forma de atuação desta empresa no exterior. A internacionalização faz parte de um bloco de estratégias gerencias", definem Madeira e Silveira (2013, p. 15).

Segundo Welch e Luostarien (1998, apud MADEIRA e SILVEIRA, 2013), a internacionalização é o aumento das operações de uma empresa em territórios estrangeiros a seu território de origem.

A internacionalização também pode ser definida como o processo que permite a atuação de uma determinada organização fora do seu mercado de origem (HITT; IRELAND e HOSKISSON, 2008, apud MADEIRA e SILVEIRA, 2013).

Apresentando diferentes meios de se atuar no exterior, a internacionalização abrange desde a exportação indireta, exportação direta, licenciamento, joint-ventures e aquisições, até investimento direto no estrangeiro (ROOT, 1998, apud MADEIRA e SILVEIRA, 2013). 
A internacionalização de empresas é um processo classificado por Barreto e Rocha (2003, apud Madeira e Silveira, 2013, p. 15) por dois tipos: "Para dentro (inward) e para fora (outward)." A internacionalização para dentro se refere à aquisição de tecnologia, obtenção de licenças ou franquias e importação. Por sua vez, a internacionalização para fora é o modelo que envolve Investimentos no exterior, concessão de licenças ou franquias e exportação.

Neste estudo, trabalharemos com os dois tipos, devido à visão da marca, que se enquadra como uma internacionalização para fora, pois ele concede a licença; e do ponto de vista do fabricante, que obtém a licença em uma internacionalização para dentro.

\subsubsection{Estratégias de internacionalização}

Arruda, Goulart e Brasil (1996) introduzem cinco estratégias de internacionalização, conforme descrito a seguir.

1- Internacionalização como evolução da capacidade de exportação: Esta estratégia se refere a uma internacionalização gradativa, dividida em três etapas: (i) Realização de experimentos de exportação para fins de teste. Nesta etapa a empresa apresenta um comportamento de observação e tem pouco envolvimento com o mercado externo; (ii) Começo da atividade de exportação com frequência; (iii) Investimentos de internacionalização em diversos segmentos com objetivos de longo prazo.

2- Internacionalização como busca de competitividade tecnológica: Esta estratégia é utilizada quando o mercado de origem da empresa é muito pequeno. Nestes casos, a empresa se internacionaliza buscando fornecer tecnologia para maiores mercados, afim de aumentar sua competitividade.

3- Internacionalização como consequência de capacidade de agregar parceiros: Através de parcerias, um empresa faz uso da tecnologia de uma outra empresa para a produção de seus próprios produtos. A tecnologia usada é muitas vezes submetida a mudanças de uma empresa para outra, uma vez que o produto e a qualidade podem não ser os mesmos.

4- Internacionalização como consequência de vantagens competitivas no mercado doméstico: Esta estratégia é direcionada a empresas de sucesso em seus países de origem. Neste caso, a empresa abre uma rede de empresas domésticas com produtos e/ou serviços semelhantes. Para garantir o sucesso desta rede, as empresas irão utilizar a mesma tecnologia, processos de produção e sistemas de gestão e controle da empresa original. 
5- Internacionalização como consequência de exposição internacional: Para o uso desta estratégias, uma empresa deve apresentar três características fundamentais: (i) Ter uma grande vantagem competitiva no mercado em que atua originalmente. Deve ser possível usar os fatores que geram essa vantagem nos novos mercados onde a empresa pretende entrar; (ii) A vantagem competitiva no mercado original deve prover um fluxo de caixa que permita investimentos para a expansão internacional da empresa; (iii) Ter opções de subsidiárias de grande porte para acolher a expansão da empresa.

\subsubsection{Fatores que interferem no processo de internacionalização}

O sucesso de um processo de internacionalização é diretamente ligado aos motivos e fatos nos quais as organizações se baseiam para tomar suas decisões, bem como à escolha da estratégia adotada, do local e da cultura. Sabendo que um mesmo elemento pode funcionar de maneira positiva ou negativa em um processo de internacionalização, é necessário fazer uma análise adequada de todos os elementos a fim de escolher as melhores opções no momento da entrada em um novo mercado (Madeira e Silveira, 2013).

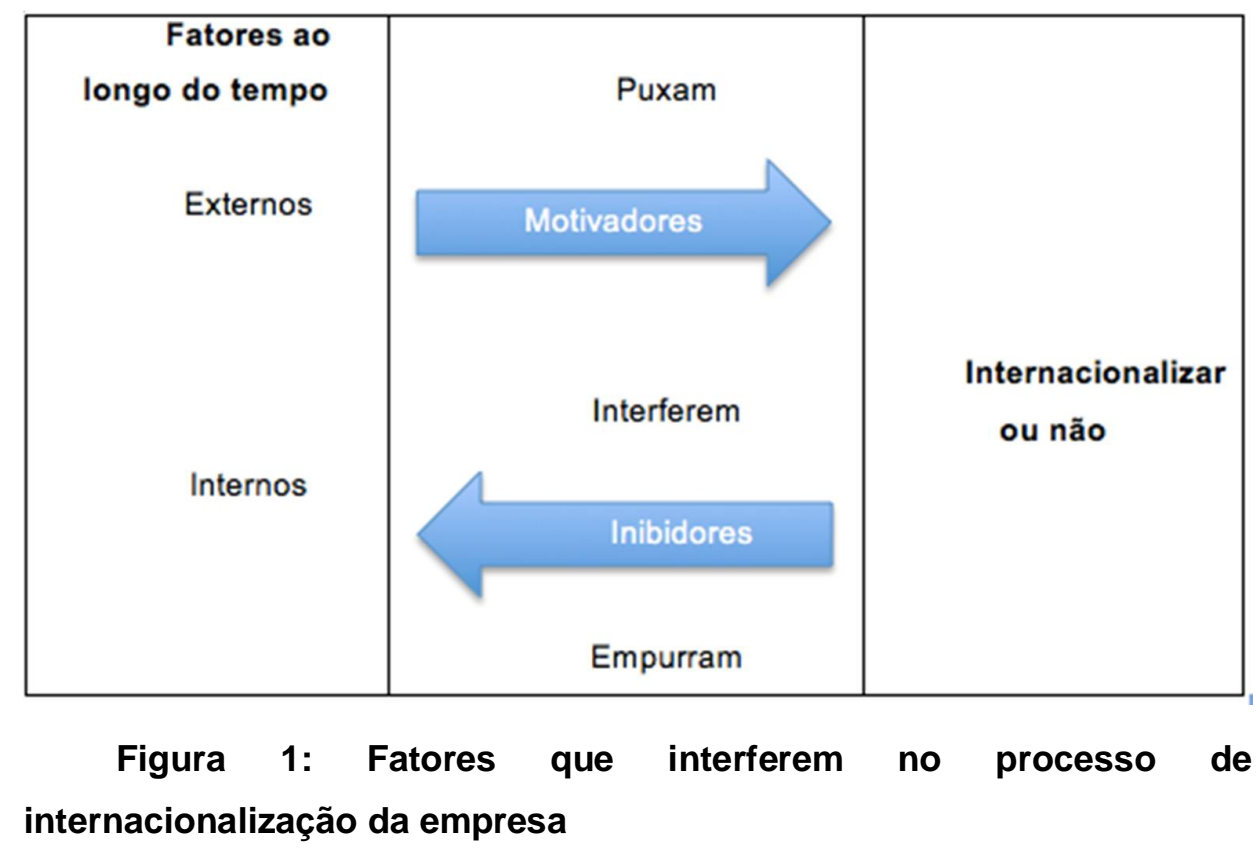

Fonte: Madeira e Silveira (2013, p. 53)

Para melhor compreender o processo de internacionalização, devem-se considerar alguns fatores apresentados no país de entrada. Esses fatores devem 
ser cuidadosamente analisados pela empresa que deseja entrar em um novo mercado, a fim de ter um maior conhecimento de tudo que pode influenciar de maneira positiva ou negativa o seu sucesso. Segundo Loureiro (1990), os principais fatores a serem considerados são políticos, econômicos, sociais, culturais, regulatórios, comerciais, financeiros e ambientais, e como eles se modificam ao longo do tempo.

Loureiro (1990) diferencia a internacionalização que apresenta investimento por parte da empresa e internacionalização sem investimento por parte da empresa. A internacionalização sem investimento acontece em licenças, franquias, exportação e contrato de gestão. Os casos onde existem investimentos se resumem a subsidiárias comerciais, subsidiárias mistas, subsidiárias de produção, joint ventures e projetos especiais.

\subsubsection{Teorias de internacionalização}

As teorias sobre internacionalização tiveram seus primórdios com grandes autores como Coase, nos anos 1930, Brian e Penrose nos anos 50 e Williamson a partir de 1971, quando as multinacionais norte americanas começaram a investir na Europa, e por consequência, as empresas europeias começaram a exportar para países vizinhos.

\subsubsection{Teoria da Firma - Custo de transação}

Ronald Coase, em 1937, publicou pela primeira vez a Teoria da Firma. Segundo Coase (1937, apud Madeira e Silveira, 2013), esta teoria está voltada para a produção da empresa relacionada com sua oferta e demanda. Ele entende a firma como uma estrutura na qual são utilizados produção, terra, capital e trabalho a fim de produzir e vender bens e serviços.

Esta teoria é baseada em processos de produção, onde o objetivo é reduzir os custos relacionados à produção e comercialização, chamados de custos de transação. No momento da internacionalização de uma empresa, deve se buscar os acordos com os menores custos de transação possíveis. Os mais frequentes custos que dizem respeito a esta teoria são os de produção, tempo, dinheiro, incertezas e restrições legais e burocráticas encontradas em transações entre vendedores e compradores (Madeira e Silveira, 2013).

Em relação aos custos de funcionamento de mercado, Saes (2008, apud Madeira e Silveira, 2013, p. 65) afirma: 
"A firma é uma relação orgânica entre agentes, que se efetiva por meio de contratos, sejam explícitos, como os de trabalho, ou implícitos, como parcerias informais. Coase mostra que são os custos de transação um dos mais importantes fatores que moldam as relações econômicas na sociedade contemporânea."

Saes (2008, apud MADEIRA e SILVEIRA, 2013) ressalta a importância de se garantir os direitos de propriedade ao começar atuar em novos países, o que resulta em negociação, um contrato organizado e o acompanhamento do cumprimento do que foi combinado entre as partes. A garantia dos direitos impede que qualquer outra empresa possa utilizar a marca protegida em seu novo território.

\subsubsection{Teoria da Firma - Visão baseada em recursos}

Os produtos são substituídos pelos recursos, quando Wernerfelt (1984, apud MADEIRA e SILVEIRA, 2013) analisa a firma de um ponto de vista estratégico. As empresas precisam de recursos para vencer as barreiras de entrada em um novo mercado, bem como as barreiras de crescimento da própria empresa. As organizações dispõem de diferentes recursos, em diferentes quantidades, e quanto melhores e maiores seus recursos, maior a vantagem competitiva da empresa. Vale ressaltar que as empresas devem basear suas estratégias em seus recursos.

Barney (1991) relaciona os recursos de uma empresa à sua vantagem competitiva. O valor do recurso tem um papel fundamental na competitividade da empresa. Um recurso valioso é um recurso raro, difícil de se ter, desenvolver ou conseguir, além de ser um recurso que permita a geração de um bem ou serviço de valor. O autor cita quatro principais indicadores de valor de recursos: o valor, a raridade, o grau de imitabilidade e de substituibilidade. $O$ grau de imitabilidade da marca é o grau de facilidade de imitar o produto ou serviço oferecido pela marca. Quando mais fácil de imitar o produto ou serviço da marca, maior o grau de imitabilidade. O grau de substituibilidade, por sua vez, esta ligado ao valor e a raridade da marca. Quanto mais valiosa e rara a marca for, menor o grau de substituibilidade.

Com uma visão mais externa às organizações, Rumelt (1984) afirma que deve-se olhar em primeiro para a indústria, afim de definir quais são os fatores de maior influência em um dado setor e então analisar se uma dada empresa apresenta ou não estes fatores. 


\subsubsection{Teoria da organização industrial}

Voltada para o ambiente externo, os três fatores analisados por Bain (1959, apud MADEIRA e SILVEIRA, 2013) são o desempenho do mercado na economia, as formas de conduta de mercado entre vendedores e compradores e os padrões existentes nas estruturas de mercado. Esse modelo de análise de mercado é o modelo de Estrutura, Conduta e Desempenho. O autor afirma que o desempenho do mercado é diretamente relacionado a estes três fatores.

A Teoria de organização industrial possibilitou a análise de posicionamento estratégico como uma estrutura conceitual. Tendo como grande objetivo a vantagem competitiva sustentável, a empresa deve conquistar uma posição exclusiva e valiosa, através de uma boa formulação de estratégia. A vantagem competitiva sustentável é um fator positivo que uma empresa possui frente a seu mercado. Ao entrar em um novo mercado, a empresa deve estar ciente das características do mercado no país onde ela está entrado afim de definir a melhor estratégia para obter vantagem competitiva. Essa vantagem é duradoura e dada por fatores tangíveis ou intangíveis, como: boa localização; preço baixo; parcerias e liquidez dos produtos. Quanto mais raro o fator de vantagem, mais vantajoso (PORTER, 1980).

\subsubsection{Licenciamento da marca}

Rabelo (2007) entende licenciamento de propriedade intelectual como a prática de conceder direitos de uso de uma determinada propriedade para terceiros. As licenças são usadas como meio de crescimento da marca e suas vendas e agregam valor ao produto ou serviço. Os bens e serviços mais frequentes no ramo de licenças são marcas de moda, clubes esportivos, filmes de cinema, programas de TV, imagens de personalidades famosas, personagens e ONGs.

A Associação Brasileira de Licenciamento explica que os direitos concedidos são por um determinado prazo. Em troca desta concessão, a empresa detentora do direito recebe uma remuneração por parte do licenciado. Geralmente, a remuneração é uma percentagem do valor das vendas brutas faturado com o uso do direito licenciado. Esse valor é pago pelo licenciado sob forma de royalties. 


\subsubsection{As vantagens do licenciamento}

Rabelo (2007) identifica como aspectos positivos para o fabricante o instantâneo reconhecimento e valorização do público, a associação a conceitos e valores ligados à licença, à economia no desenvolvimento da marca e ao aumento das vendas.

Ao começar a fabricar e distribuir uma marca sob licença, o fabricante se beneficia do fato que esta marca já existe. Uma marca que concede licenças é uma marca que já está bem estabelecida em pelo menos um mercado e seu valor e reconhecimento já existem. Por estar fabricando e distribuindo uma nova marca, o fabricante passa a ter um maior portfólio e um maior volume de vendas. (RABELO, 2007).

A marca, por sua vez, tem como vantagem a geração de uma receita adicional sem maiores custos, facilidade e rapidez para explorar diferentes segmentos e mercados, o desenvolvimento de suas atividades e a geração de valor e fortalecimento da propriedade licenciada (RABELO, 2007).

Ao ceder o direito de uso de sua marca, os custos de produção e distribuição passam a ser da empresa fabricante. Deste modo, a empresa detentora irá apenas receber parte da receita obtida com a vendas sem ter nenhum custo. A facilidade e velocidade na exploração de um novo mercado é dada pelo fato que a marca não precisa construir fábricas e lojas. O licenciamento permite que um fabricante já estabelecido em um mercado, com fábrica e lojas já operantes, passe a fabricar e vender uma nova marca mediante concessão dos direitos. Ao licenciar e ter seus produtos fabricados e distribuídos em um novo mercado, a marca está desenvolvendo suas atividades, ampliando seu território de atuação e criando novas parcerias. A geração de valor é dada pelo crescente acesso aos produtos, uma vez que através do licenciamento, uma marca terá seus produtos comercializados em mais países. O aumento das vendas é uma consequência do início da produção e distribuição em um novo mercado que antes não era explorado (RABELO, 2007).

\subsubsection{As implicações do licenciamento}

Vicente (2010) explica que para ser realizado o licenciamento, a marca deve estar devidamente registrada ou com pedido de registro aberto no INPI. Não é possível se conceder o direito que não se possui, deste modo, se não houver registro ou pedido de registro, a marca não pode ser contratualmente 
licenciada. Quando a marca é oficialmente licenciada, termos contratuais a protegem de uma maior exploração que o acordado. Com uma licença, o detentor original do direito apenas fornece a uma terceira parte o direito de uso da marca.

Segundo Rabelo (2007), a detentora da licença (fabricante), deve apoiar a marca, com propaganda e promoção, além de transmitir os corretos valores na fabricação dos produtos e em sua distribuição. A marca deve supervisionar todo o trabalho feito pelo licenciado (fabricante) para garantir que a imagem da marca está sendo preservada.

Mesmo tendo em vista um crescimento da marca, deve-se atentar em manter o controle sobre este crescimento, uma vez que caso ocorra um crescimento descontrolado, a licença pode trazer um resultado contrário ao esperado, um enfraquecimento da marca. Este cuidado é relacionado aos valores criados pela marca, que não podem ser esquecidos caso as vendas se acelerem. Para tal, é fundamental uma boa escolha de parceiro para se licenciar, diminuindo os riscos de insucesso (RABELO, 2007).

Esses fatores visam principalmente preservar a identidade, conceito e força da marca licenciada. Outro ponto crucial para esta preservação é a escolha da forma de distribuição, uma vez que os pontos de venda determinam em grande parte o público que será atingido.

Tanto fabricante quanto marca devem estar cientes que a comunicação que visa o fortalecimento da marca deve ser voltada para o longo prazo. A publicidade promocional é a técnica mais usada para fins de divulgação de produtos ou serviços, incentivando assim a demanda. As empresas devem estar atentas para não confundir publicidade promocional e ações de promoção, pois estar visam objetivos de curto prazo, explica Rabelo (2007).

Pode-se fazer um link entre os pontos acima citados para um sucesso de longo prazo com a negociação contratual, onde, como falado, o posicionamento cooperador pelas partes é fundamental para o sucesso.

\subsubsection{O setor de licenças no Brasil}

Segundo a ABRAL (Associação Brasileira de Licenciamento), o Brasil é um dos países que mais fatura em licenciamento no mundo. Deste modo, o setor de licenças desenvolve um importante papel na economia brasileira. Os únicos países com faturamento em licenciamento maior que o Brasil são: EstadosUnidos, Japão, Inglaterra, México e Canadá. 
Este faturamento vem crescendo muito desde 2012, quando a média no varejo era de 12 bilhões de reais. A previsão para 2015 é alcançar um faturamento de 13,7 bilhões de reais no território Brasileiro.

Veja na tabela abaixo outros dados fornecidos pela ABRAL.

Tabela 1: Dados do setor de licenças brasileiro (ABRAL)

\begin{tabular}{|c|c|c|c|}
\hline Organizacional & $\begin{array}{l}\text { Propriedades } \\
\text { mais exploradas }\end{array}$ & $\begin{array}{c}\text { Segmentos que } \\
\text { mais utilizam } \\
\text { licenciamento }\end{array}$ & $\begin{array}{c}\text { Taxa de } \\
\text { Royalties sobre } \\
\text { o preço de venda } \\
\text { do varejo }\end{array}$ \\
\hline $\begin{array}{c}500 \text { empresas } \\
\text { Licenciadas }\end{array}$ & $\begin{array}{c}70 \% \text { propriedades } \\
\text { ligadas ao } \\
\text { entretenimento }\end{array}$ & 1 - Confecção & $\begin{array}{c}\text { Brinquedos } 10 \text { a } \\
12 \%\end{array}$ \\
\hline $\begin{array}{l}600 \text { Licenças } \\
\text { disponíveis }\end{array}$ & $\begin{array}{c}20 \% \text { propriedades } \\
\text { corporativas }\end{array}$ & 2 - Brinquedo & $\begin{array}{c}\text { Roupas e } \\
\text { Calçados 10\% }\end{array}$ \\
\hline $\begin{array}{c}75 \% \text { de licenças } \\
\text { estrangeiras }\end{array}$ & $\begin{array}{l}10 \% \text { propriedades } \\
\text { ligadas ao esporte }\end{array}$ & 3 - Papelaria & Cadernos $10 \%$ \\
\hline $\begin{array}{l}50 \text { agências } \\
\text { licenciadoras }\end{array}$ & & 4 - Personal Care & $\begin{array}{c}\text { Acessórios } 8 \text { a } \\
12 \%\end{array}$ \\
\hline $\begin{array}{c}1.300 \text { empregos } \\
\text { diretos }\end{array}$ & & & $\begin{array}{c}\text { Eletrônicos } 8 \text { a } \\
10 \%\end{array}$ \\
\hline $\begin{array}{c}\text { Milhares de } \\
\text { empregos indiretos }\end{array}$ & & & $\begin{array}{c}\text { Cosméticos } 5 \text { a } \\
8 \%\end{array}$ \\
\hline
\end{tabular}

Fonte: www.abral.org.br - O Setor

\subsection{Negociação}

"Negociação é um processo de comunicação bilateral, com o objetivo de se chegar a uma decisão conjunta" (FISHER e YURI, 1985, apud MARTINELLI 1998, p. 18). Sendo a negociação um processo que envolve duas partes, ambas devem assumir em determinados momentos o papel de emissor e receptor de mensagem, buscando acordos satisfatórios para ambas as partes.

Martinelli (1998) também explica que ter ambos os lados satisfeitos e com suas necessidades básicas atendidas é de suma importância em uma negociação. Esta é uma visão mais moderna sobre o assunto. No passado, cada 
parte buscava atender seus próprios interesses, sem procurar saber se a outra parte também estava satisfeita. Com o passar do tempo, a maioria dos autores passou a definir esse tipo de negociação como ganha-perde (onde para uma parte sair ganhando, a outra precisa sair perdendo) (MARTINELLI, 1998). Essa prática se tornou cada vez menos utilizada pelas empresas por apresentar consequências negativas até mesmo para o lado que ganha, como por exemplo, a quebra do acordo em curto ou médio prazo por parte da empresa que estava perdendo com essa negociação e o fato que e as duas empresas envolvidas dificilmente voltariam a negociar uma com a outra, pois a parte prejudicada se protegeria contra novas possíveis lesões (MARTINELLI, 1998).

Por sua vez, conhecida como negociação ganha-ganha e cada vez mais buscada pelas organizações, esta proporciona um relacionamento duradouro, futuras negociações e uma relação cada vez melhor entre os envolvidos. Em uma negociação ganha-ganha, ao contrário do que pode-se pensar, as partes não necessariamente deixam de ganhar mais para a outra também poder ganhar. Em muitos casos, as necessidades e interesses são complementares, e não conflitantes. (MARTINELLI, 1998).

A negociação ganha-ganha se resume a satisfazer as duas partes negociantes. Para caracterizar uma negociação ganha-ganha, os negociadores deve considerar as necessidades da outra parte, sem esquecer de suas próprias necessidades. A sinceridade, justiça e coerência são fundamentais para uma relação ganha-ganha. Muitas vezes, os interesses das partes são diferentes, deste modo, todos os interesses das duas partes podem ser atendidos (THOMAS, 1992).

\subsubsection{A pré-negociação}

Watkins (2006) afirma que muito se ganha e muito se perde antes mesmo de os negociadores sentarem-se a mesa, dito este que se veste perfeitamente à negociação de licenças entre grifes europeias e fabricantes latino americanos pois uma reunião presencial é agendada apenas quando já existe um avanço significativo nas negociações. Em outras palavras, o autor entende que bons negociadores são hábeis na preparação e planejamento das negociações, e este fato permite ganho e perdas antes mesmo da conversa começar.

Além do preparo para os determinados assuntos em questão, a preparação dos debatedores de qualidade se faz a partir de experiências irrefletidas. Em outras palavras, o preparo de uma negociação se faz em toda a 
vida, com o acúmulo daquilo que pensamos e fazemos, tendo grande consideração a formação acadêmica e a linha de raciocínio seguida por cada indivíduo, explica Zajdsznajder (1985). O autor afirma ainda que é muito significativo que as sociedades em que o debate assume tanta importância descuidem quase inteiramente da preparação retórica, abandonada, no seu entendimento, como uma arte de prover de ornamentos os discursos, enfatizando assim a importância deste recurso.

No que tange à pré-negociação, Zajdsznajder (1985) inclui em seu repertório preparativo prever as possíveis reivindicações de seus interlocutores, afim de ter respostas satisfatórias para ambas as partes.

A escritora Camila Lam (2014) recomenda se munir de todas as informações sobre o assunto da negociação antes que ela aconteça. Lam também cita Ernesto Berg (2004), consultor e especialista em negociação: "Se você não domina o assunto e o interlocutor é expert, ele vai acabar pressionando e você não conseguirá negociar".

Wanderley (1998, apud LAM, 2014) afirma que uma boa preparação é fundamental para aproveitar todas as oportunidades. Para uma boa preparação, o autor inclui cenários positivos e negativos, abordando assim todas as possibilidades.

\subsubsection{Tipos de negociação}

Watkins (2006) identifica dois tipos de negociação, a simples e a complexa, conforme pode ser visto na Figura 3.

Tabela 2: Negociações corporativas: Simples x Complexas

\begin{tabular}{|l|l|}
\hline \multicolumn{1}{|c|}{ Simples } & \multicolumn{1}{c|}{ Complexas } \\
\hline - Uma questão & - Várias questões \\
- Duas partes & - Muitas partes \\
- Um nível & - Vários níveis \\
- Autônoma & - Negociações inter-relacionadas \\
\hline
\end{tabular}

Fonte: Watkins (2006, p. 77)

Conforme pode ser visto comparando-se com a Tabela 2, as licenças internacionais de fabricação e distribuição podem se enquadrar como uma negociação complexa. 
Watkins (2006) cita as características de cada ponto de uma negociação complexa:

- Várias questões: Cria-se valor estabelecendo-se ligações entre as questões e ao longo do tempo (e também por meio de captura de valor).

- Muitas partes: Tenta-se encontrar equilíbrio entre as relações e os resultados.

- Vários níveis: Lida-se com representantes e o processo interno de tomada de decisões.

- Negociações inter-relacionadas: Usam-se informações e sincronizam-se grupos de negociações.

\subsubsection{Estratégias de negociação}

Zajdsznajder (1985, p. 57-61) aponta 15 estratégias de negociação. Estudaremos as 10 estratégias mais voltadas para a negociação de licenças.

1- "Identificar os pontos fortes e fracos." As partes envolvidas em uma negociação definem suas forças e suas fraquezas. Quanto maior a necessidade pelo objeto em negociação por uma das partes, maior será a fraqueza desta parte. A necessidade é algo negativo em uma negociação, pois ao precisar imperativamente de algo, a parte é obrigada a sacrificar o que for preciso para atingi-lo. Caso o grau de necessidade seja alto mas tiverem alternativas disponíveis para suprir esta necessidade, então é visto como uma força por parte do necessitado, pois tendo opções ele não é obrigado a aceitar o que for necessário para atingir um objeto específico na negociação. Os recursos do negociador e a urgência em obter o objeto negociado podem ser forças ou fraquezas, dependendo de seu grau. Um alto grau de recursos é uma força, um alto grau de urgência é uma fraqueza, e vice-versa.

2- "Determinar o poder de barganha, identificando que parte se encontra relativamente mais forte." A estratégia a ser traçada e seguida pelo negociador deve depender do seu poder de barganha. Um alto ou baixo poder de barganha será definido ao comparar as forças e fraquezas frente á outra parte. Quanto maiores as forças da empresa, maior será seu poder de barganha.

3- "Identificar os aspectos principais e secundários do objeto de negociação." Os diferentes pontos do objeto em negociação podem ter uma importância maior ou menor para as partes envolvidas. Esses pontos, como preço, prazos, direitos e deveres, devem ser ponderados entre as partes, a fim 
de identificar o grau de interesse de cada parte para cada ponto e definir os objetivos das partes e suas estratégias.

4- "Estabelecer os limites máximo e mínimo e os resultados considerados satisfatórios relativamente ao objetivo da negociação." Tendo definidos os graus de poder de barganha e os pontos do objeto da negociação de maior e menor importância entre as partes, é possível identificar o máximo e o mínimo que se pretende chegar no final da negociação. Dentro desta margem de máximo ao mínimo, o negociador deve estabelecer um resultado que considere satisfatório, de maneira a encerrar a negociação quando este for atingido.

5- "Determinar a intensidade com que se buscará endurecer ou mostrar flexibilidade em relação aos diversos aspectos da negociação e em relação a esta como um todo." Os graus de poder de barganha e importância dos pontos do objeto da negociação para cada parte também permitem a parte definir sua flexibilidade ao longo da negociação. Quanto maior a importância do ponto e maior o poder de barganha, menos a parte será flexível, e vice-versa.

6- "Delinear a proposta inicial e sua justificativa." A formulação da proposta inicial deve ser baseada no máximo definido pela parte. Desta maneira, além de buscar os resultados mais positivos, a parte também terá margem para fazer concessões. A proposta deve ser acompanhada de uma justificativa realista e viável, deste modo, mesmo as propostas mais ousadas devem ser justificadas.

7- "Delinear propostas posteriores à inicial." Ao formular a proposta inicial, propostas alternativas também devem ser elaboradas. Deste modo, caso a proposta inicial seja negada, a parte irá dispor de uma outra proposta, bem elaborada e não improvisada. Mesmo que a segunda proposta não seja a ideal, dependendo das circunstâncias da negociação, ela pode servir de base para a formulação de outra proposta. A justificativa da proposta é imprescindível para qualquer proposta.

8- "Definir as informações que se pretende prestar." De maneira a não expor seus pontos vulneráveis na negociação, através dos quais a outra parte poderia transformar em poder de barganha, cada parte deve definir previamente à negociação quais informações pretende ou não fornecer para a outra parte. Quanto mais informações concedidas, maior será a confiança e transparência entre as partes, facilitando um acordo ganha-ganha. No entanto, algumas informações estratégicas devem ser guardadas em sigilo de maneira a não comprometer de maneira negativa a parte detentora da informação.

9- "Identificar as informações que se pretende obter de maneira direta ou indireta da outra parte." Assim como devem ser definidas a informações a serem 
fornecidas, também devem ser definidas as informações que se pretende adquirir da outra parte. Estas informações podem ser obtidas de duas maneiras, direta ou indiretamente. As informações obtidas de forma direta se resumem àquelas onde a outra parte concorda em fornecer a informação. A maneira indireta induz a outra parte a fornecer a informação através de respostas de outras perguntas, que de uma maneira ou de outra levem à dedução da informação procurada.

10-"Prever alternativas de ação prováveis da outra parte e que respostas dar a elas." Não é possível prever exatamente a estratégia da outra parte, no entanto, considerar as mais prováveis permite definir a melhor resposta e estratégia para cada uma destas possibilidades. A outra parte pode optar por uma maior ou menos flexibilidade, uma maior ou menor transparência, uma força ou fraqueza frente a certos pontos do objeto da negociação e pode também visar uma relação de curto, médio ou longo prazo com a outra parte. Essas variáveis devem ser estudas visando identificar os prováveis comportamentos da outra parte ao longo da negociação e elaborar as melhores respostas para tais. Ao prever estas alternativas, o negociador garante obter o melhor negócio possível diante de qualquer postura da outra parte. Tendo se preparado para qualquer situação que a negociação possa chegar, o negociador tem suas propostas e respostas pré-definidas para as mais variadas atitudes que a outra parte possa vir a ter. Assim, é dispensado o uso de um improviso, no qual provavelmente o negociador não teria soluções tão eficazes e positivas quanto aquelas que ele previu antes da negociação.

Por sua vez, Thomas (1992) apresenta 5 estratégias: Competir, Colaborar, Conceder, Evitar e Acomodar-se, conforme Figura 2 e descrições abaixo. 


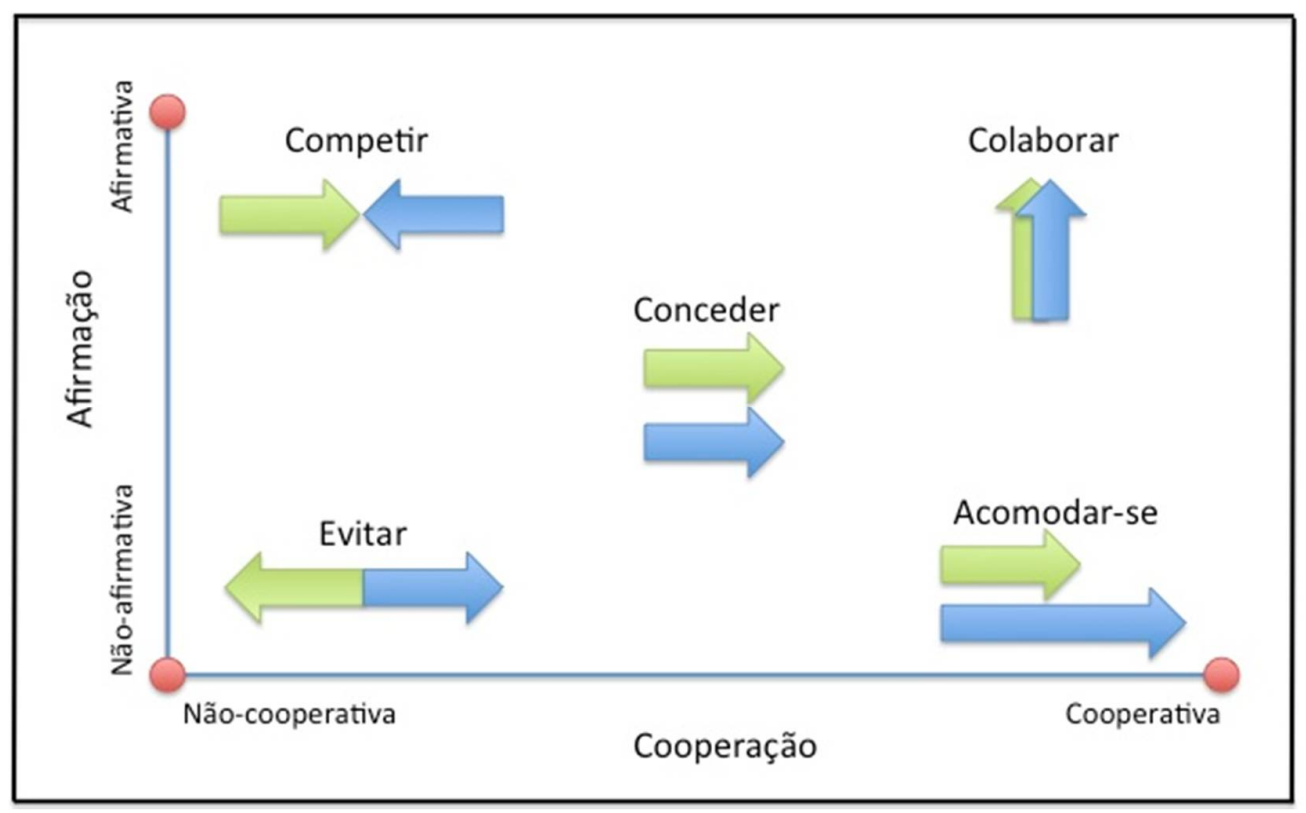

Figura 2: Estratégias de negociação

Fonte: Thomas (1992, p. 668)

Competir (Competing): Relação ganha-perde. Nesta estratégia, o negociador procura atender prioritariamente a suas necessidades e motivações. Usando todo e qualquer meio necessário para atingir suas vontades, o negociador apresenta uma forte tendência pela busca do poder. Esta postura não necessariamente significa uma busca pela vitória, mas também pode ser adotada para uma defesa de direitos, interesses ou posições.

Evitar (Avoiding): Relação perde-perde. O negociador busca não se envolver ou comprometer, deixando de lado seus interesses pessoais. Esta estratégia é empregada frente a temas que o negociador prefere não abordar por diversos possíveis motivos. Este comportamento muitas vezes leva ao desvio do tema, adiamento ou esquecimento.

Acomodar-se (Accommodating): Relação perde-ganha. Procurando não entrar em conflito com a outra parte, o negociador aceita a proposta dentro do possível para sua realidade. Neste caso, os próprios interesses são deixados de lado e as requisições da outra parte são atendidas. Essa atitude geralmente significa concordância com a opinião alheia, obediência ou simplesmente generosidade.

Colaborar (Collaborating): Relação ganha-ganha. Estratégia contrária a de Competir, nesta o negociador busca satisfazer os objetivos do outro negociador, levando em consideração também seus próprios interesses. A colaboração visa resultados mais proveitosos para ambos, uma vez que essa postura é mantida 
em diversos tópicos do tema. Favorável para ambos os lados em determinados momentos, esta estratégia é baseada em objetividade, sinceridade e coerência. Muitas vezes utilizada para casos de desacordo, a colaboração busca soluções criativas e bilateralmente justas, facilitando os diálogos e o sucesso da negociação.

Conceder (Compromising): Relação perde-ganha: O negociador prioriza a vontade do outro negociador frente a sua própria vontade. Neste caso, o negociador concessor abre mão de algo para a outra parte. Essa estratégia visa uma negociação mais saudável, onde o bom entendimento e respeito para com o outro são fundamentais. Outra vantagem de se conceder é ganhar poder de barganha em um futuro tópico da negociação no qual você realmente necessite que sua vontade seja feita.

\subsubsection{Negociadores}

Martinelli (2011) completa que o negociador deve levar em conta dois pontos fundamentais: "A importância do resultado obtido e a importância do relacionamento passado, presente e futuro com a outra parte." Depois, divide os negociadores em quatro tipos:

Negociador Analítico: Sempre buscando a lógica e racionalidade, o negociador analítico se certifica de que a estratégia traçada está sendo seguida e implementada. O mesmo analisa a outra parte procurando esclarecer a racionalidade da sua posição.

Negociador Efetivo: Tem pleno conhecimento dos assuntos em pauta para a negociação. Se mantém em perguntas realistas e respostas esclarecedoras. Quando necessário está apto a fornecer informações complementares e garante a abordagem de todos os pontos fundamentais.

Negociador Relativo: Age como facilitador da negociação, onde seu papel é garantir o bom entendimento das partes, através de amplo conhecimento das reações humanas bem como o lado psicológico. Busca construir a confiança entre os negociadores, o que geralmente resulta em uma negociação ganhaganha.

Negociador Intuitivo: Profissional de muita visão, apresenta ideias e caminhos para tornar a negociação mais proveitosa e positiva para ambos os lados. Não apenas desenvolve ideias como também se certifica das implicações ao médio e longo prazo. Com base no momento presente da negociação e no seu intuito, consegue supor o caminho que a negociação está tomando. 


\subsubsection{A persuasão}

Zajdsznajder (1985) diz que a criação da persuasão se deu pelos sofistas na Grécia Antiga e, desde então, a visão da sociedade em relação a esta prática é negativa. Desde sua criação, a persuasão é entendida como uma maneira de influenciar a outra parte de uma maneira errada. O autor explica a persuasão é uma tática em que o persuasor é vencedor quando a outra parte é de fato influenciada.

A persuasão tem uma alegação e uma situação básica. A alegação é que a proposta apresentada é a melhor que se poderia oferecer. A situação é quando aquele que ouve aceita o que lhe é dito, e o aceita porque de alguma maneira fica convencido. Sem dúvida, o estar convencido é como se ter admitido vencido, ou seja, ter-se entregue ao que o outro propôs (ZAJDSZNAJDER, 1985).

Seguindo o pensamento de Watkins (2006), existem duas maneiras fundamentais de se persuadir uma pessoa.

A primeira maneira se baseia nos interesses de quem se busca persuadir, assim como o que é importante para ele e os fatores que ele considera em suas escolhas. Esta maneira está relacionada com a implicação estratégica de "entender quem está tomando decisões em cada organização e com base no quê", falada anteriormente. Mas como chegar a esses interesses? São citadas duas estratégias: entender os interesses alheios através de uma perspectiva estrategicamente escolhida e influenciar as percepções alheias por meio do framing(prática de influenciar o que as pessoas pensam e sentem sobre uma questão encorajando-as a pensar sobre ela de determinada maneira).

A segunda maneira é por meio de alternativas, mostrando o conjunto de opções que nossos interlocutores acreditam estar disponíveis para eles, onde as percepções que eles têm de suas alternativas por meio da indução de escolhas é influenciada pelo persuasor.

\subsubsection{Relação entre os players}

Para uma longa parceria entre marca e fabricante, é necessário que ambas as partes estejam satisfeitas com os resultados apresentados ao desenrolar de suas atividades juntos, ou seja, a estratégia adotada pelos players pode definir a duração e o sucesso da parceria. Como fica evidente na Tabela 2, 
feita por Watkins (2006), o ideal é que ambos os players estejam posicionados para cooperar na negociação, pois é onde ambos têm ganhos, sendo assim mantendo o contrato ativo. Esta postura "positiva" também ajuda em muito o trabalho do intermediário, que alcançará um acordo favorável para ambas as partes com maior facilidade.

\begin{tabular}{|c|l|l|l|}
\hline \multicolumn{2}{|c|}{} & \multicolumn{2}{c|}{ Eles } \\
\cline { 2 - 4 } & \multicolumn{1}{|c|}{ Cooperar } & $\begin{array}{l}\text { Cooperar } \\
\text { Você obtém ganhos } \\
\text { modestos e eles } \\
\text { também. }\end{array}$ & $\begin{array}{l}\text { Você perde muito, } \\
\text { eles ganham muito. }\end{array}$ \\
\cline { 2 - 4 } & Competir & $\begin{array}{l}\text { Você ganha muito, } \\
\text { eles perdem muito }\end{array}$ & $\begin{array}{l}\text { Você perde e eles } \\
\text { também, mas não tanto } \\
\text { quanto se um de vocês } \\
\text { houvesse cooperado. }\end{array}$ \\
\hline
\end{tabular}

Figura 3: Relação cooperação x competição entre os players

Fonte: LAM (2014)

Para Wanderley (1998, apud LAM, 2014), qualquer negociação é um diálogo e o importante é fazer com que a conversa não vire um monólogo.

Segundo Reck e Long (1990), é fundamental cultivar boas relações com pessoas que você deseja negociar. Ao usarem como exemplo a negociação de um pequeno empréstimo, como o valor de um almoço, os autores mostram a importância de ter alguma relação com quem cederia o empréstimo. Este fato também tem impacto em negociações de grande porte. A relação entre as partes considerada por Reck e Long (1990) como ideal é a relação ganha-ganha. Nesta relação, os envolvidos na negociação criam um sentimento de confiança um pelo outro, o que tende a levar a parceria ao sucesso e a novas negociações entre os mesmos.

Os dois autores concluem o raciocínio dizendo que chegar a um acordo satisfatório não é na verdade a meta final de uma negociação, mas sim obter um desempenho satisfatório. Eles explicam que qualquer acordo, não importa o quão favorável seja, passa a não ter valor algum se a outra parte optar por não o honrar. (RECK e LONG, 1990). 


\section{Métodos e procedimentos de coleta e de análise de dados do estudo}

Este capítulo informa e descreve as etapas de coleta de dados do estudo, as fontes selecionadas para coleta de dados, os procedimentos e instrumentos utilizados para a coleta de dados, a forma de tratamento dos dados e suas análises e por fim as limitações do estudo.

Foi utilizado o método de pesquisa exploratória, onde três empresas, sendo uma intermediadora, um fabricante e uma marca, foram entrevistados.

método de pesquisa exploratória foi escolhido porque permite uma abordagem de negociações de licenças na prática. Desde modo, podemos utilizar os resultados obtidos nesta pesquisa para uma comparação com as teorias apresentadas neste estudo.

O setor de licenciamento foi escolhido para análise por ser uma potente alternativa de internacionalização que nem sempre é considerada. Com poucos ou nenhum custo, o licenciamento pode ser mais vantajoso para uma empresa do que a importação ou a abertura de novas fábricas.

\subsection{Métodos de pesquisa utilizados}

A coleta de dados deste estudo consiste em três entrevistas em profundidade, baseadas em questionários previamente estruturados. As perguntas dos três roteiros foram baseadas nos conceitos e teorias apresentados na revisão de literatura (capítulo 2).

A primeira entrevista foi direcionada a uma empresa brasileira que faz a intermediação de negociações entre grifes europeias e fabricantes latino americanos. A segunda entrevista foi feita com um fabricante brasileiro que produz e distribui diversas linhas de produtos de empresas europeias sob licença. A terceira e última entrevista foi aplicada em uma marca francesa que, além de ter política de licenças, já concedeu licenças em 6 países da América Latina. Deste modo, abordamos as três partes envolvidas em uma negociação de licença entre fabricantes latino americanos e marcas europeias. 


\subsection{Fontes de informação selecionadas para coleta de dados no estudo}

As três empresas entrevistadas têm relação direta com o tema estudado.Para a entrevista direcionada à empresa intermediadora, o entrevistado foi o Sr. Hugo João Layolle, Presidente da Fashion Licensing Ltda., empresa com 20 anos de mercado e atualmente representante de seis marcas europeias, são elas: Cerruti; Ted Lapidus; Guy Laroche; Karl Lagerfeld; New Man e Enrico Corevi.

Em relação à pesquisa direcionada ao fabricante brasileiro, o entrevistado foi o Presidente e proprietário do Grupo Vila Romana S.A., Sr. Carlos Isaac. A Vila Romana mantém desde 2001 até hoje negociações com a Fashion Licensing e distribui os produtos que fabrica para quase todos os países da América do Sul e Central, além de ter 35 lojas distribuídas nos principais estados do país. Em 2011 o fabricante abriu sua comercialização para o mercado multimarcas, procurando expandir a marca para mercados em que não estava presente.

$\mathrm{Na}$ terceira entrevista, a empresa abordada foi a grife francesa Yves Saint Laurent. A entrevistada foi a Gerente de licenças da YSL, Sra. Françoise Gauci. A Yves Saint Laurent era representada pela Fashion Licensing e teve diversas licenças de sucesso em seis países da América Latina; México, Panamá, Brasil, Chile, Argentina e Colômbia.

\subsection{Procedimentos e instrumentos de coleta de dados utilizados no estudo}

Todas as três entrevistas foram agendadas previamente e as perguntas foram apresentadas somente na hora da realização da entrevista.

As perguntas foram elaboradas procurando confirmar a aplicação das teorias de negociação, internacionalização e licenciamento da marca ao longo de uma negociação de licenças envolvendo as três partes, fabricante, marca e intermediadora.

A primeira entrevista, com o Presidente da Fashion Licensing, foi realizada presencialmente em seu escritório no Jardim Botânico. A entrevista foi gravada e a duração foi de aproximadamente uma hora. As perguntas desta entrevista foram divididas em três partes, conforme pode ser visto no Anexo 1. A primeira parte, que conta com seis perguntas, é destinada a um melhor e claro entendimento da atividade que uma empresa intermediadora exerce e como se 
dá o processo destas negociações. As perguntas da segunda parte são baseadas nas teorias e conceitos vistos ao longo deste estudo e totalizam quatorze perguntas. Tendo entendido que o problema deste estudo é do ponto de vista da intermediadora, a terceira parte da entrevista conta com três perguntas que buscam entender a relação que a marca e o fabricante analisados apresentam com seus parceiros depois da assinatura do contrato, ao longo da parceria. Estas duas perguntas possibilitam uma comparação entre a postura adotada pelas partes ao longo da negociação e suas consequências na relação entre às mesmas posteriormente à negociação, ou seja, ao longo da parceria.

As duas entrevistas seguintes, com o Presidente da Villa Romana e a Gerente de Licenças da Yves Saint Laurent foram realizadas via Skype, gravadas e depois transcritas. Estas tiveram uma menor duração, cerca de trinta minutos cada, pois apresentaram apenas as perguntas relacionadas às teorias $e$ conceitos de negociação, internacionalização e licenciamento da marca, introduzidas no capítulo de revisão de literatura (ver Anexos 2 e 3). Ambas as entrevistas dispõem de 13 perguntas.

\subsection{Formas de tratamento e análise dos dados coletados para o estudo}

O dados coletados foram tratados de três maneiras. Os dados coletados na primeira parte da entrevista com a intermediadora passaram por uma análise de conteúdo, uma vez que neste primeiro momento desejava-se obter um maior conhecimento e familiarização com a atividade desta empresa e com o processo de negociação de licenças que a mesma intermedia.

A segunda maneira de tratamento dos dados coletados foi reconhecer as semelhanças e diferenças existentes entre as respostas fornecidas nas três entrevistas e as teorias e conceitos apresentados no capítulo de revisão de literatura deste estudo. Esta comparação permite identificar quais teorias apresentadas na revisão de literatura são postas em prática pelos negociadores

entrevistados e as estratégias que eles adotam ao longo de negociações de licenças.

O terceiro tratamento de dados envolve as respostas obtidas nas entrevistas com a marca e o fabricante e as respostas obtidas na terceira parte da entrevista com a intermediadora. As pesquisas com a marca e o fabricante foram destinadas a identificar as estratégias que eles adotam ao longo de negociações de licenças. A terceira parte da entrevista com a intermediadora foi 
destinada a identificar a relação que a marca e o fabricante estudados apresentam ao longo da parceria. Por meio de uma análise de comparação entre estes dados, podemos concluir, do ponto de vista da intermediadora, quais são as melhores práticas de negociação para uma melhor relação entre as partes ao decorrer da parceria.

\subsection{Limitações do estudo}

A primeira limitação é o fato de ter sido entrevistada apenas uma empresa para cada parte de uma negociação de licença internacional, ou seja, uma empresa representando a marca, uma empresa representando o fabricante e uma empresa representando a intermediária. Deste modo, não podemos comparar comportamentos dentro de uma mesma parte, apenas entre as partes.

Assim como a quantidade de empresas entrevistadas, também é uma limitação o fato de apenas empresas de um país para cada parte da negociação ter sido entrevistada. Não podemos estudar assim as diferenças e semelhanças entre os fabricantes da América Latina ou entre as marcas europeias. Para a intermediadora o país foi o Brasil, assim como para o Fabricante. A marca entrevistada é francesa.

A terceira limitação foi o canal utilizado para as entrevistas com a marca e o fabricante. O Skype induz os interlocutores a uma conversa objetiva, evitando possíveis comentários complementares ou formulações de novas perguntas derivadas das respostas fornecidas.

A última limitação é o método exploratório, onde o viés do entrevistador é induzido por sua interpretação dos dados. 


\section{Resultados}

Este capítulo apresenta e analisa os principais resultados alcançados e suas implicações. O mesmo é divido em três seções.

A primeira seção apresenta a empresa intermediadora de negociação de licenças - a Fashion Licensing. Nesta seção, é exposto o processo de negociação de uma licença entre marcas europeias e fabricantes latino americanos, além de detalhar a atividade que a intermediadora exerce ao longo deste processo.

A seguir, temos uma comparação entre as estratégias introduzidas neste estudo e as estratégias usadas pela intermediadora, fabricante e marca ao decorrer de negociações de licenças internacionais.

Por último, é feita uma ligação entre a as estratégias usadas pela marca e pelo fabricante ao longo da negociação e a relação entre elas ao longo da parceria, descrita pelo intermediário. Esta última seção irá responder ao problema desta pesquisa, pois esta conclui, do ponto de vista do intermediário, quais são as estratégias e práticas de negociação que geram os melhores resultados na relação entre a marca e o fabricante a longo prazo.

\subsection{A Empresa Fashion Licensing}

A Fashion Lincensing foi criada em 1995. Sua atividade consiste em representar grifes europeias na América Latina, levando a estas grifes oportunidades de licenças em países Latino Americanos. Além da apresentar estas oportunidades, a Fashion Licensing intermedia a negociação entre a grife e o candidato à licença, e uma vez o contrato assinado, acompanha a atividade de produção, distribuição e cumprimento dos termos contratuais.

O Presidente da Fashion Licensing é e sempre foi o Sr.Hugo João Layolle, e conta com dez funcionários em sua equipe.

A atividade da Fashion Licensing começou com apenas um cliente, a empresa francesa Yves Saint Laurent. Com o passar dos primeiros meses e sucessos em licenças representando a Yves Saint Laurent, a Fashion Licensing passou a representar também a Ungaro, Louis Féraud, Daniel Hechter, Christian Lacroix, Charles Jourdan, Austin Reed. Estas marcas não são mais 
representadas pela Fashion Licensing devido a três fatores: (i) fim da vigência do contrato; (ii) insucesso nas licenças ou (iii) mudanças nas estratégias das empresas que originaram a interrupção do sistema de licenças. Hoje, as marcas representadas pela Fashion Licensing são a Cerruti, Ted Lapidus, Guy Laroche, Karl Lagerfeld, New Man e Enrico Corevi.

\subsubsection{O processo de negociação de licenças}

O começo do processo se dá por parte da Fashion Licensing (FL). Esta empresa age como representante da marca e busca identificar oportunidades de parcerias com fabricantes latino americanos, onde, através de licenças de fabricação e distribuição o fabricante irá produzir e distribuir os produtos da marca em nome dela. Uma vez a oportunidade identificada, a empresa FL entra em contato com a marca e apresenta a oportunidade. Esta apresentação consiste em algumas informações padrão, são elas: o nome do fabricante, seu território de atuação, que linhas ele fabrica, de que outras grifes ele é licenciado, sua capacidade de produção, sua situação financeira, industrial e de distribuição, o seu posicionamento de imagem e vendas, além da situação atual do mercado onde este fabricante está inserido.

Caso a oportunidade seja do interesse da grife, que geralmente é, pois a Fashion Licensing age como representante dos interesses da marca, é formulada uma proposta pela empresa europeia, e transmitida para a empresa da América Latina através da Fashion Licensing. Ao demonstrar interesse em uma oportunidade de licença, ou seja, começar a atuar em um novo território através de uma parceria, a organização europeia está buscando principalmente expandir seu território, vendas e imagem.

Em seguida, o fabricante responde à Fashion Licensing, informando se há ou não interesse em fechar esta parceria. Caso haja interesse por parte da grife, a FL começa a negociar com o candidato à licença os principais pontos de um contrato de licença (território, royalties, produtos, duração, mínimos contratuais, percentual obrigatório de comunicação e o cronograma de abertura de novas lojas). Ao chegar a um acordo, a Fashion Licensing redige a proposta, confirma que este foi o acordado com o candidato à licença e manda a proposta para a grife. A grife diz se concorda ou não com a proposta e se necessário, a FL renegocia com o candidato.

Uma vez a proposta aprovada por ambas as partes, a FL encaminha a proposta ao departamento jurídico da grife, que complementará o contrato de 
licença padrão da grife com as informações específicas dessa negociação. Com este contrato pronto, a FL o manda para o fabricante candidato. Na maioria das vezes, o candidato assina de primeira, mas em alguns casos algumas pequenas modificações podem ser solicitadas.

\subsection{A aplicação das teorias na prática}

Esta seção faz uma comparação entre as estratégias apresentadas no capítulo de revisão de literatura deste estudo e as estratégias que os entrevistados apontaram, e será divida em três partes: (i) Estratégias da literatura $x$ Estratégia da intermediadora; (ii) Estratégias da literatura $x$ Estratégias do Fabricante e (iii) Estratégias da literatura $x$ Estratégias da Marca.

\subsubsection{A aplicação das teorias pela intermediadora}

A Fashion Licensing ( $F L)$ apresenta uma postura flexível, pois evita conflitos. É adotada uma postura inflexível apenas em termos não negociáveis, como por exemplo os limites do território de vendas e a necessidade de aprovação dos produtos antes da fabricação em larga escala. Neste momento os conflitos também são evitados, através de justificativas racionais acerca das exigências obrigatórias.

No que tange à pré-negociação, o Sr. Layolle confirma as estratégias apresentadas por Zajdsznajder (1985, p. 135) e Lam (2014), tendo as experiências acumuladas ao longo da vida profissional, pessoal e acadêmica como grande influenciadoras em suas negociações. Outro ponto confirmado é relativo às informações buscadas antes das negociações. No entanto, a empresa entrevistada não prevê as possíveis reivindicações e contrapropostas da outra parte: "Eu não faço um repertório em relação ao que pode ser pedido pela outra parte. Eu faço uma pauta dos tópicos a serem abordados e minhas exigências. Quando a outra parte contradiz umas de minhas exigências ou propostas, com a experiência que eu acumulei ao longo dos anos, eu automaticamente tenho a resposta para sua reivindicação.". Logo, não aplica a teoria de Zajdsznajder (1985, p. 136), onde ele defende que essas previsões ajudam a preparar as melhores respostas possíveis.

Em relação às estratégias de negociação propostas por Zajdsznajder(1985, p. 57-61), a Fashion Licensing demonstra seguir a maioria delas. Ela identifica as forças e fraquezas das marcas e da intermediadora, 
identifica a parte com o maior poder de barganha, identifica os aspectos principais e secundários na negociação para cada parte, estabelece limites mínimos junto com seu cliente (a marca) para que a parceria seja interessante e define as informações que pretende obter da outra parte antes do início da reunião. O Sr. Layolle não utiliza uma das estratégias de negociação de Zajdsznajder, pois raramente define informações a serem deixadas em sigilo. Segundo o Sr. Layolle, as propostas alternativas não são elaboradas antes da reunião pois suas elaborações dependem de muitas variáveis que são sabidas apenas na resposta da primeira proposta. Ao receber esta resposta, o Presidente da Fashion Licensing elabora uma nova proposta dentro de uma margem que ele julga aceitável. Em relação à não definição de informações sigilosas, a FL defende a maior transparência possível, deste modo, não fornece a informação apenas em raras exceções.

O uso da persuasão descrita por Watkins (2006, p. 97) não é feito pelo entrevistado, pois ele não procura um ponto de vista que permita identificar os interesses da outra parte e nem tenta influenciar a maneira de pensar da mesma. A FL entende que a força da marca é o fator de maior importância, não precisando usar técnicas psicológicas para influenciar o fabricante. " Não uso técnicas de persuasão, é na força da marca que o interesse deve estar." disse o Sr. Layolle.

Quase todos os aspectos positivos e negativos de se licenciar apresentados por Rabelo (2007) são os mesmo que os citados pelo Sr. Layolle, como listado a seguir: a geração de uma receita (muitas vezes alta) sem a contrapartida de custos; a exploração de um novo mercado; dificuldade de homogeneidade das linhas de produto e difícil coerência na distribuição.

Ao dividir as vantagens competitivas entre as vantagens frente aos concorrentes internacionais e frente aos concorrentes nacionais, a Fashion Licensing apresenta a mesma visão que Rumelt (1984), tendo uma visão mais voltada para o mercado como um todo, e não apenas à própria organização No entanto, a Fashion Licensing não faz uma comparação com o ambiente externo como um todo. Neste caso, a visão de vantagem competitiva mostrada pela FL é mais próxima da visão de Barney (1991, p. 99) que a baseia em recursos: "O valor; a raridade e o grau de imitabilidade e substituibilidade." As vantagens indicadas pela Fashion licensing são: marca internacional; o posicionamento da marca; a imagem desenvolvida e a notoriedade da marca. Cada um destes quatro fatores se enquadram nas vantagens intituladas por Barney (1991, p. 99). 
Tendo todas essas características de negociação da Fashion Licensing definidas, podemos concluir que a estratégia de negociação predominante é a de colaboração, introduzida por Thomas (1992), uma vez que ela busca acordos satisfatórios para ambas as partes e visa um relacionamento a longo prazo.

Podemos concluir também que o tipo de negociador da Fashion Licensing é efetivo e intuitivo, pois tem um profundo conhecimento sobre os assuntos em pauta e desenvolve novas ideias junto à marca (Martinelli, 2011). Negociador relativo também se enquadra no perfil da $F L$, pois facilita a relação e comunicação entre as partes, assim como a negociação como um todo.

\subsubsection{A aplicação das teorias pelo fabricante}

Segundo o entrevistado da Vila Romana (VR), a empresa sempre procura evitar conflitos. Quando é preciso, ou seja, quando uma das cláusulas contratuais propostas não é aceitada pela Vila Romana, então a mesma busca um consenso com a outra parte através da negociação, sem conflitos." $E u$ sempre evito conflitos. Porém, se houver no contrato uma ou várias clausulas que podem ser prejudiciais para a minha empresa ou a uma boa exploração da licença, negocio essas clausulas. Caso não tiver um resultado satisfatório na negociação destas clausulas, então a licença em questão não é do interesse da minha empresa e a negociação não segue adiante.", afirma o Sr. Isaac.

O Sr. Isaac segue o mesmo pensamento que Zajdsznajder (1985, p. 135) em relação ao peso que as experiências da vida têm no momento da negociação, no entanto a empresa não procura se preparar para as possíveis reivindicações da outra parte, como é aconselhado por Zajdsznajder (1985, p. 136). O motivo desta não preparação, segundo o entrevistado, é que a formulação de uma resposta para uma reinvindicação é automática para os negociadores da VR, pois os mesmos conhecem suas melhores opções.

Ainda em pré-negociação, o Presidente da Vila Romana, assim como é recomendado por Lam (2014), procura se munir de todas as informações referentes ao assunto da negociação. Essas informações consistem na maioria das negociações de licenças em: imagem da marca; notoriedade da marca; receptividade potencial da marca no mercado; rede de lojas multimarcas; explorações anteriores da marca.

A VR demonstra utilizar grande parte das estratégias de negociação de Zajdsznajder (1985, p. 57-61). Primeiramente, a Vila Romana analisa suas forças e fraquezas através do seu grau de interesse pela marca, reportando que 
quanto maior o grau de interesse, maior a fraqueza, pois se torna uma necessidade e sendo assim trás uma certa dependência pela marca. O Sr. Isaac avalia em um segundo momento o poder de barganha. Segundo ele, o poder de barganha também está diretamente relacionado ao grau de interesse pela marca. Em uma negociação de licença, os itens que serão mais afetados pelos poderes de barganha são os royalties a serem pagos pelo fabricante para a marca e as obrigações em vendas ou volume mínimos estabelecidos anualmente. A Vila Romana também identifica os aspectos primários e secundários em uma negociação de licenças, citando como primários (i) taxa de Royalty; (ii) mínimos contratuais; (iii) produtos licenciados e (iv) assistência técnica (produto e publicidade),e como aspectos secundários apenas o prazo de pagamento dos royalties, que pode ser trimestral ou semestral. Em relação ao estabelecimento de limites máximos e mínimos, como a VR vai faturar em função da sua própria produção e vendas, não há o que exigir da marca. No entanto, a Vila Romana faz uma projeção de vendas com a marca no seu mercado. Essa Projeção irá revelar se a parceria é interessante ou não. Os negociadores da Vila Romana também definem quais informações serão mantidas em sigilo, que basicamente se constituem de: o volume de vendas que a empresa tem com outras marcas e as especificações das cláusulas que a empresa tem com estas outras marcas. A última estratégia de Zajdsznajder (1985, p. 57-61) seguida pela VR é a de definir as informações que pretende obter da outra parte previamente à negociação. As informações procuradas mais frequentemente são: a localização de lojas, o volume de vendas, detalhes da assistência técnica prestada ao licenciado em nível de produto, publicidade, merchandising e conceitos "corner" e boutique (conceitos da exposição dos produtos, materiais promocionais e objetos dentro das lojas e nas vitrines)

A única estratégia de Zajdsznajder (1985, p. 57-61) que não é adotada pela Vila Romana é a de dispor de propostas alternativas caso a primeira proposta não seja aceita. Neste caso, o Sr. Isaac usa a estratégia de tentar tornar a primeira proposta mais interessante para a outra parte gradativamente, até que a proposta seja aceita ou chegar a um ponto que deixe de ser interessante para a própria VR. Na entrevista deste estudo o Presidente da Vila Romana disse: " Eu não disponho de outras propostas. Eu vou apresentar a minha proposta inicial. Caso algum dos pontos não seja aceito pela outra parte, eu vou tentar torná-lo mais interessante para a marca. A minha flexibilidade nesta melhoria da proposta será definida pelo meu grau de interesse pela licença da marca.". 
A técnica de persuasão do entrevistado é muito semelhante à técnica descrita por Zajdsznajder (1985, p. 63), pois procura mostrar que a proposta feita é a melhor possível. "Através da argumentação, procuro mostrar para meus interlocutores os fundamentos da minha posição e convencê-los de que a minha proposta é a melhor possível para ambas as partes." (Sr. Isaac).

Assim como Rumelt (1984), a Vila Romana identifica as suas vantagens competitivas frente à indústria. O Sr, Isaac aponta como as principais vantagens competitivas ao ter uma licença: uma exposição da marca a nível mundial e um maior reconhecimento da marca pelo público. "As principais vantagens são se diferenciar frentes às marcas nacionais, se beneficiando da imagem mundial e 0 reconhecimento da marca europeia junto ao público." (Sr. Isaac).

Considerando os dados coletados relativos à Vila Romana, podemos concluir que esta empresa usa predominantemente uma estratégia de colaboração. Em alguns momentos também pode ser percebida a estratégia de concessão, como no momento da reformulação de suas propostas, onde a VR procurar tornar a proposta mais interessante para a outra parte gradativamente (Thomas, 1992). O uso da concessão, mesmo que excepcional, é de grande influência nos resultados obtidos, pois ele pode ser o fator decisivo para evitar um conflito na negociação e assim não comprometer a relação entre as partes a curto, médio e até longo prazo.

Os negociadores da Vila Romana, por sua vez, seriam classificados por Martinelli (2011) como negociadores analíticos, pois têm estratégias bem traçadas e seguidas, além de analisar pontos estratégicos da outra parte.

\subsubsection{A aplicação das teorias pela marca}

A Yves Saint Laurent (YSL), assim como a Fashion Licensing e a Vila Romana, evita confrontos ao longo da negociação, portanto apresenta uma postura flexível. A Sra. Gauci explica que uma boa relação entre as partes é fundamental para o sucesso da parceria e que conflitos não permitiriam esta boa relação: " Para as cláusulas que são negociáveis, sempre evitamos conflitos procurando soluções que convenham para ambas as partes. Em uma licença, é fundamental um bom entendimento e relação entre a marca e o fabricante, por isso o conflito nunca é do nosso interesse.".

A entrevistada utiliza também técnicas de pré-negociação de Zajdsznajder (1985, p. 135) e Lam (2014). Além de usar a experiência ao seu favor no momento da negociação, ela também procura obter todas as informações 
possíveis sobre o assunto da negociação. Essas informações são trazidas pela empresa intermediadora e são muito importantes para a formulação de propostas.

Entretanto, a YSL não prepara respostas para as possíveis reivindicações previamente à negociação, como é recomendado por Zajdsznajder (1985, p. 136). A empresa argumenta que as reivindicações devem ser apresentadas através da intermediadora, e junto com ela serão formuladas as respostas ou propostas.

Comparando as estratégias de Zajdsznajder (1985, p. 57-61) com as estratégias adotadas pela Yves Saint Laurent, percebemos uma grande semelhança entre elas. As forças e fraquezas das partes são estudadas e podem ser úteis para determinar se a parceria é interessante ou não, bem como podem ser usadas como argumentos ao longo da negociação. A YSL também define os aspectos mais importantes na negociação, que são: o posicionamento preço; o "sourcing" (a fonte das matérias primas, ou seja, os fornecedores do fabricante) e o tipo de distribuição. A empresa complementa ainda que os mercados da América Latina são muito pouco integrados, de maneira que mesmo países vizinhos podem ter estes três aspectos principais bem diferentes. São estabelecidos também limites mínimos para que a parceria seja interessante. Além de serem definidos internamente pelos negociadores da Yves Saint Laurent, estes mínimos constam em contrato. Caso a porcentagem de vendas brutas a ser paga em forma de royalty não alcançar o mínimo contratual, então é o mínimo que deverá ser pago para a marca, e não a porcentagem de venda brutas. Por fim, a YSL também estabelece as informações que pretende obter da outra parte, sendo as mais frequentes: financeiras; industriais; de distribuição; de posicionamento imagem e volume de vendas.

Duas das estratégias de Zajdsznajder (1985, p. 57-61) não são empregadas pela Yves Saint Laurent. A primeira é a identificação do poder de barganha das partes. A gerente de licenças das YSL diz não interpretar como poderes de barganha, mas define a principal força que uma marca e um fabricante podem ter, a força da marca e a qualidade do produto. A segunda teoria não empregada é a definição das informações a serem ou não divulgadas. A YSL procura ser o mais transparente possível e diz não ter motivo para esconder nenhuma informação.

A Sra. Gauci não faz uso de nenhuma das técnicas de persuasão apresentadas por Zajdsznajder (1985) e Watkins (2006). "Talvez inconscientemente, mas conscientemente acho que não", disse a gerente. 
Com isso, pode-se dizer que Thomas (1992) classificaria a Yves Saint Laurent em unicamente uma estratégia, a de colaboração. A empresa demonstra tentar chegar a acordos positivos para ambas as partes e onde os interesses de ambos sejam atendidos.

O tipo de negociador da Yves Saint Laurent segundo Martinelli (2011) seria o negociador analítico, uma vez que esse foca na elaboração, execução e acompanhamento das estratégias.

As estratégias de internacionalização apresentadas por Arruda, Goulart e Brasil (1996) que são usadas pela Yves Saint Laurent são: "Internacionalização como consequência de capacidade de agregar parceiros" e "Internacionalização como consequência de exposição internacional". A primeira estratégia é percebida pela necessidade de parceiros para produzirem seus produtos no processo de internacionalização. Para a estratégia referente à exposição internacional, a empresa Francesa apresenta as características fundamentais. A grande vantagem competitiva em seu mercado original é o forte reconhecimento da marca. Esse reconhecimento é mundial, logo esse fator gera vantagem competitiva também nos outros países onde a empresa pretende entrar.

Com relação às Teorias de Internacionalização, a teoria da firma, Saes (2008) ressalta a importância de se preservar os direitos das marcas durante o processo de internacionalização. Para preservar seus direitos, a Yves Saint Laurent registra legalmente sua marca e logotipo nos países onde a mesma está introduzida, na classe de registro a qual ela pertence.

Ainda na teoria da firma, Wernerfelt (1984) fala das vantagens competitivas como caminhos para vencer barreiras. A YSL identifica como a principal vantagem de usar o licenciamento o custo de importação, que segundo o entrevistado pode ser considerada a maior barreira de marca internacionais. Fabricando nos próprios países onde os produtos são vendidos, a empresa evita o elevado custo de importação e dispõe assim de um preço para o público mais competitivo. Frente aos concorrentes nacionais, as duas vantagens identificadas pela YSL são: A internacionalidade da marca e a criatividade no estilo.

\subsection{As melhores práticas e estratégias para uma relação de longo prazo}

Em termos de canais de comunicação, os encontros presenciais promovem os melhores resultados na relação entre marca e fabricante. Segundo

a intermediadora, reuniões presenciais facilitam não somente uma relação 
profissional como também pessoal. Tendo em vista que as licenças são idealmente duradouras, é essencial um bom entendimento interpessoal entre as partes envolvidas, a fim de minimizar os conflitos e facilitar a comunicação e acordos. Os canais secundários mais usados em negociações de licenças internacionais são o Skype, telefone e e-mail. Estes canais são de grande utilidade pois são independentes da distância entre o emissor e receptor da mensagem, o que pode ser muito útil em negociações internacionais. Estes canais são tidos como secundários pois são considerados complementares, enquanto que os encontros presenciais são a base para uma boa relação e entendimento na negociação."Uma licença sendo normalmente uma relação duradoura, é fundamental criar desde a negociação uma relação transparente, com o melhor entendimento pessoal possível entre as partes. Para isto, o ideal são reuniões presenciais, onde as partes podem criar uma relação profissional e pessoal. Meios de comunicação como Skype, telefone e e-mail também são muito importantes, pois se trata de negociações entre diferentes países, o que torna encontros físicos nem sempre viáveis. Reuniões presenciais são a base para uma boa negociação e os outros meios são complementares." (Sr. Layolle).

Fazendo uma comparação entre o desenvolvimento da parceria e as estratégias usadas pela marca e pelo fabricante ao longo da negociação, identificaremos as melhores estratégias para uma relação de longo prazo entre marca e fabricante.

Como foi concluído, tanto a marca quanto o fabricante apresentam aspectos de uma estratégia predominante de colaboração. Além da colaboração, o fabricante também utiliza em determinados momentos a estratégia de concessão.

Os negociadores de ambas as partes foram identificados como analíticos. Tendo em vista que as estratégias usadas pelas partes é fundamental para o sucesso da parceria, os negociadores analíticos apresentam um importante papel nestas negociações e em seus sucessos, pois são eles que garantem a aplicação das estratégias traçadas.

Do ponto de vista da intermediadora, tanto o fabricante quanto a marca apresentam uma relação cordial, pessoal, positiva, de longo prazo e de trabalho com seus parceiros. Os contratos são quase sempre renovados e as parcerias são de muito sucesso para ambas as partes.

Deste modo, podemos sugerir que as melhores estratégias para uma relação de longo prazo são, por parte do fabricante, a colaboração e a 
concessão, e por parte da marca, a colaboração. Em relação à postura dos negociadores, a analítica é a melhor opção. 


\section{Conclusões e recomendações para novos estudos}

Esse trabalho teve como objetivo identificar as estratégias e práticas de negociação que geram os melhores resultados na relação entre uma marca europeia e um fabricante brasileiro a longo prazo. O foco do estudo recaiu em estratégias e técnicas de negociação.

Em um primeiro momento, para melhor entender a internacionalização de uma empresa através do sistema de licenciamento da marca, analisamos as teorias de internacionalização de Madeira e Silveira (2013), Loureiro (1990), Barney (1991) e Rumelt (1984) e as teorias de licenciamento de marca de Rabelo (2007) e os dados fornecidos pela ABRAL.

Após estabelecer uma base de conhecimentos sobre os processos de internacionalização e mais especificamente o licenciamento, estudamos a negociação como um todo, passando por técnicas de pré-negociação de Zajdsznajder (1985) e Lam (2014), os tipos de negociação apresentados por Watkins (2006), as estratégias de negociação de Zajdsznajder (1985) e Thomas (1990), as técnicas de persuasão introduzidas por Watkins (2006) e Zajdsznajder (1985), até a relação entre os players de Reck e Long (1990) e Lam (2014).

Para atingir os objetivos pretendidos foi realizada uma pesquisa qualitativa suportada por três entrevistas em profundidade. A primeira entrevista foi feita com a maior empresa brasileira intermediadora de negociações de licenças de fabricação e distribuição de produtos da alta costura europeia, a Fashion Licensing. A segunda foi dirigida a um grande fabricante brasileiro, a Vila Romana. Este fabricante tem contratos de licenças com grandes grifes europeias e distribui os produtos que fabrica em quase todos os países da América Latina. A última entrevista foi feita com uma das maiores e mais tradicionais marcas do setor de moda e luxo do mundo, a empresa francesa Yves Saint Laurent, que também tem política de licenças e contratos com fabricantes latino americanos. Deste modo, abordamos as três partes envolvidas em uma negociação de licença internacional: a intermediadora, o fabricante e a marca.

Os dados obtidos foram tratados de modo a responder às perguntas formuladas no problema do estudo. As conclusões foram muito satisfatórias e as perguntas foram respondidas. 
A estratégia de negociação predominante tanto na intermediadora quanto no fabricante e na marca é a de colaboração (THOMAS, 1992). Essa estratégia provou levar a acordos satisfatórios para todas as partes envolvidas e uma relação de longo prazo. O fabricante foi a única parte que demonstrou em alguns momentos usar também a estratégia de concessão. Este fato é muito importante para a conclusão, pois em alguns momentos da negociação, a concessão pode ser responsável por evitar conflitos, uma vez que usar a estratégia de colaboração não é o suficiente para se chegar a um acordo, como por exemplo, em cláusulas padrão e fixas de um contrato de licença.

Além das estratégias usadas pelas empresas, identificamos também o tipo de negociador de cada uma das três. A intermediadora demonstrou ter negociadores efetivos e intuitivos. Por sua vez, os negociadores do fabricante e da marca são analíticos (MARTINELLI, 2011).

Essas foram as principais conclusões chegadas com o conteúdo da revisão de literatura e a análise dos dados obtidos nas entrevistas em profundidade.

\subsection{Sugestões e recomendações para novos estudos}

A primeira sugestão para estudos futuros é analisar o processo, as estratégias, as relações e os resultados de negociações de licenças de outros setores. O setor de brinquedos seria uma boa opção para esta análise, pois é o segundo segmento que mais utiliza o licenciamento e tem a maior taxa de royalties (10 a 12\%) sobre o preço de venda do varejo dentre os segmentos com licenciamento.

Outra sugestão seria, se mantendo no setor da alta costura, pesquisar quantitativamente intermediadoras, marcas e fabricantes. Estas pesquisas poderiam ter foco em negociação, internacionalização e/ou licenciamento.

Uma terceira sugestão seria estudar as taxas de crescimento das empresas ao abrirem licenças. O estudo poderia incluir um comparativo de crescimento da marca entre segmentos, entre países e entre marcas. O objetivo seria identificar, além do grau de atratividade de se abrir licenças, as melhores oportunidades de licenciamento e como estas são exploradas pelas empresas.

A última linha de estudo que poderia ser seguida é uma análise comparativa entre as atividades das marcas de alta costura francesas independentes e através de licenças. Este estudo possibilitaria identificar as diferenças entre estes dois meios de atuação (independente e licenciamento), 
revelando as especificações e os lados positivos e negativos de cada um deles, e por fim concluir qual é o mais lucrativo para a marca. 


\section{Referências Bibliográficas}

ARRUDA, C.A.; GOULART, L.; BRASIL, H.V. Estratégias de Internacionalização: Competitividade e Incrementalismo. In: Fundação Dom Cabral. Internacionalização de empresas brasileiras. Rio de Janeiro: Qualitymark, 1996.

Associação Brasileira de Licenciamento (ABRAL). O setor. Disponível em: http://abral.org.br/o-setor/. Acesso em: 26 maio 2015.

BARNEY, J. B. Firm, Resources and Sustained Competitive Advantage. Journal of Management, v. 17, n. 1, 1991.

FUSÕES da UE somaram US\$ 1 trilhão. Folha de São Paulo, São Paulo, 02 Jan. $2000 . \quad$ Disponível em: http://www.1folha.uol.com.br/fsp/dinheiro/fi0201200013.htm. Acesso em 23 de maio de 2015.

LAM, C. 5 dicas para não perder uma negocição. Exame, São Paulo,29 Abril 2014. Disponível em: http://exame.abril.com.br/pme/noticias/5-dicas-para-naoperder-uma-negociacao. Acesso em 21 de abril de 2015.

LOUREIRO, F. Internacionalização de empresas brasileiras: Estratégias e ação.São Paulo,1990. Dissertação (Mestrado) - Faculdade Economia, Administração e Contabilidade, Universidade de São Paulo.

LUDERS, G. Veja por que o mercado de moda no Brasil é o que mais cresce. Revista Exame, São Paulo, 22 Jan. 2014. Disponível em: http://exame.abril.com.br/revista-exame/edicoes/1057/noticias/a-moda-que-valebilhoes. Acesso em 23 de Maio de 2015.

MADEIRA, A. B.; SILVEIRA, J. A. G. Internacionalização de empresas teorias e aplicações. São Paulo: Saint Paul, 2013.

MARTINELLI, D. P.; ALMEIRDA, A. P. Negociação e solução de conflitos. São Paulo: Atlas, 1998.

MARTINELLI, D. P. Negociação - Conceitos e Aplicações Práticas. 2ª Ed., São Paulo: Saraiva: 2011.

MICHAEL, W. Shaping the game: The New Leader's Guide to Effective Negotiation. Boston: Harvard Business School Press, 2006.

PORTER M. E. Competitive strategy: Techniques for analyzing industries and competitors: with a new introduction. New York: Free press, 1980.

RABELO, A. Licenciamento e Estratégia de Marcas. Licensing Brasil n. 7, nov/dez 2007. Disponível em: http://www.administradores.com.br/artigos/marketing/licenciamento-e-estrategia- 
de-marcas/20431/. Acesso em: 12 de maio de 2015

RECK, R.; LONG, B. G. A Negociação ganha-ganha: Como negociar acordos favoráveis e duradouros. Tradução de Ricardo Gouveia. 1.ed. São Paulo: Saraiva, 1990.

RUMELT, R. P. Towards a Strategic Theory of the Firm. In: LAMB, R.B. (Ed.). Competitive Strategic Management, Englewood Cliffs, NJ: Prentice-Hall. 1984.

THOMAS, K. Conflict and negotiation process in organizations. Handbook of industrial \& Organizational Psychology, 2 ed., vol. 3. Palo Alto: Consulting Psychologists Press, p. 668, 1992.

VICENTE, F. Licenciamento de marca x Franchising: como escolher o contrato correto? Grupo Bittencourt, São Paulo, 19 agosto 2010. Disponível em: http://www.bittencourtconsultoria.com.br/artigos/licenciamento-de-marca-xfranchising-como-escolher-o-contrato-correto.html. Acesso em 31 Maio 2015.

WATKINS, M. Negociação. Harvard Business Essentials. Rio de Janeiro: Record, 2004.

ZAJDSNAJDER, L. Teoria e Prática de Negociação. Rio de Janeiro: José Olympio Editora, 1985. 


\section{Anexo 1}

\section{Entrevista - Intermediadora}

Hugo João Layolle - Presidente da Fashion Licensing Ltda.

\section{Parte 1}

\section{Qual é a atividade da Fashion Licensing?}

- A Fashion Licensing representa grifes Europeias na América Latina, levando a estas grifes oportunidades de licenças em países Latino Americanos, intermedia a negociação entre a grife e o candidato a licença e uma vez o contrato assinado, acompanha a atividade de produção, distribuição e cumprimento dos termos contratuais.

\section{Em que ano a Fashion Licensing foi criada?}

$-1995$

\section{Em que território a Fashion Licensing atua?}

- A FL representa apenas grifes Europeias. Todos os Fabricantes licenciados trazidos pela FL para suas representadas são Latino Americanos.

\section{Quantas e Quais grifes a Fashion Licensing representa?}

- A primeira empresa cliente da FL foi a Yves Saint Laurent. DepoisvieramUngaro, Louis Féraud, Daniel Hechter, Christian Lacroix, Charles Jourdan, Austin Reed. Estas marcas não são mais representadas pela Fashion Licensing devido a três fatores; Fim da vigência do contrato, insucesso nas licenças ou mudanças nas estratégias das empresas que originaram 0 interrupção do sistema de licenças. Hoje, as marcas representadas pela FL são 
a Cerruti, Ted Lapidus, Guy Laroche, Karl Lagerfeld, New Man e Enrico Corevi. Então no momento a Fashion Licensing representa 6 grifes.

\section{Como se dá o início de uma representação?}

- A Fashion Licensing age em dois tipos de negociação. O primeiro tipo é a negociação do Contrato de Agente de Representação, entre a Fashion Licensing e uma grife Europeia. O segundo tipo é a negociação de contrato de licença, entre a grife Europeia e a candidata a licenciada na América Latina, agindo como intermediadora desta negociação.

O primeiro passo é dado pela $\mathrm{FL}$, que busca identificar oportunidades de licenças nos países da América Latina. Tendo profundo conhecimento do mercado da moda na europa, o Presidente da Fashion Licensing sabe quando uma marca está disponível para abrir uma licença. Tendo também grande conhecimento dos fabricantes latino americanos que fabricam sob licença, a Fashion Licensing também sabe quando um fabricante está a procura de novas

licenças. Após identificar um fabricante/mercado em potencial para licenças, é hora de identificar a grife Europeia certa para a oportunidade em questão. A FL busca então uma marca que corresponda as necessidades dos potenciais licenciados e que tenha política de licenciar. A Fashion Licensing entra então em contato com a grife Europeia sem falar sobre nenhuma possibilidade de licença, afim de evitar que a empresa faça contato direto com o potencial licenciado. A abordagem mais usada é uma apresentação da Fashion Licensing, expressão do interesse em representar a marca na América Latina e informando que existem possibilidades muito atrativas de licenciar.

Por sua vez, a Fashion Licensing busca saber se a marca tem as três características fundamentais para ser uma marca interessante para licenças, são elas: A notoriedade da marca (se a marca é conhecida no mercado), o posicionamento de imagem (pontos de vendas, preço, qualidade do produto e comunicação)e a assistência técnica que a marca presta para seus licenciados. Em assistência técnica existem três pilares, que são: o produto, a comunicação e 0 conceito boutique (Conceito/decoração externo das lojas, conceito/decoração interna das lojas, merchandising e comunicação visual).

Caso haja interesse por parte da grife, começa a negociação do contrato de representante. Este contrato geralmente não demanda muita negociação. $A$ FL envia seu contrato proposta para a marca e caso a marca queira mudar algum item do contrato, a FL na maioria das vezes adota uma postura flexível. 
Os principais itens deste contrato são: território, duração, linhas de produto e remuneração.

O poder de barganha neste momento é muito maior por parte Fashion Licensing, que nesse momento ocupa o posto de candidata a representante, ela é a única representante de licenças renomada na América Latina e Europa, com o maior conhecimento do mercado. Mesmo com grande poder de barganha, a Fashion Licensing não procura o valor máximo, mas sim valores realistas e justos, de maneira a manter uma relação saudável e ganha-ganha com seus clientes. A contratação da Fashion Licensing não traz nenhum risco para a marca, pois não há nenhuma remuneração até que algum contrato de licença trazido pela FL seja assinado e tem uma duração de normalmente 24 meses. Caso nenhum contrato de licença for assinado durante este prazo, o contrato de representante estará automaticamente terminado. No entanto, caso haja um ou mais contratos de licenças assinado(s) durante este período, então o contrato de representante será vigente em quanto o(s) contrato(s) de licença estiver(em) válido(s).

\section{Qual é o processo negociação de licenças, do início ao fim?}

- Tendo um contrato de representante assinado, a FL entra em contato com um potencial fabricante. Caso haja interesse por parte do fabricante em ser licenciado da marca representada, a FL informa a grife sobre a oportunidade, informando o nome do fabricante, sua localização, que linhas ele fabrica, de que outras grifes ele é licenciado, a capacidade de produção e as vezes algumas outras informações. Caso haja interesse por parte da grife, a Fashion Licensing começa a negociar com o candidato a licença os principais pontos de um contrato de licença (território, royalties, produtos, duração, mínimos contratuais, percentual obrigatório de comunicação e o cronograma de abertura de novas lojas). Ao chegar a um acordo, a Fashion Licensing redige a proposta, confirma que este foi o acordado com o candidato a licença e manda a proposta para a grife. A grife diz se concorda ou não com a proposta e se necessário, a FL renegocia com o candidato.

Uma vez a proposta aprovada por ambas as partes, a FL encaminha a proposta ao departamento jurídico da grife, que complementará o contrato de licença padrão da grife com as informações específicas dessa negociação. Com este contrato pronto, a FL o manda para o fabricante candidato. Na maioria das 
vezes, o candidato assina de primeira, mas em alguns casos algumas pequenas modificações podem ser solicitadas.

\section{Parte 2}

7. Em uma negociação de licença com fabricantes latino americanos, você evita conflitos com a outra parte ou encara qualquer tipo de situação para ter êxito na vontade da Marca?

- Evito qualquer tipo de conflito. A situação na qual eu não posso abrir mão da minha posição é que o licenciado tem que aceitar as exigências apresentadas no contrato de licença. Caso um licenciado recuse uma das exigências do contrato de licença, o intermediário explica que todos os contratos de todas as marcas tem basicamente as mesmas exigências. O licenciado, mesmo que pretendendo não cumprir as exigências as quais ele se opôs, como não há recuo por parte da marca ou intermediário, assina o contrato.

8. Você diria que a experiência que você acumulou ao longo da vida, seja pessoal, acadêmica ou profissional, ajuda nas suas negociações? De que maneira?

- A experiência ajuda muito. Em negociações anteriores, já me deparei com as mais variadas situações e, por consequência, suas soluções. Sendo assim, conheço todas as minhas opções em qualquer caminho que a negociação possa seguir.

9. Antes de uma negociação com marca ou fabricante, você faz um repertório para prever as possíveis reinvindicações de seus interlocutores, afim de ter as melhores respostas/propostas para ambas as parte?

- Eu não faço um repertório em relação ao que pode ser pedido pela outra parte. Eu faço uma pauta dos tópicos a serem abordados e minhas exigências. Quando a outra parte contradiz umas de minhas exigências ou propostas, com a experiência que eu acumulei ao longos dos anos, eu automaticamente tenho a resposta para sua reivindicação. Mesmo as questões que não cabem apenas a mim decidir, mas também a marca, eu não prevejo junto com ela as possíveis 
reivindicações do fabricante, por que com o "se" nunca se chega a lugar nenhum, além de que, a marca sempre irá dizer que ela quer o que ela pede, e não o que a outra parte pode vir a reivindicar.

10. Antes de uma negociação, você procura se munir de todas as informações referentes ao assunto? Você percebe uma vantagem na negociação para o lado que tem mais informações sobre o assunto?

- Eu procuro me munir de todas as informações referentes ao candidato (seu histórico como empresa, sua situação financeira, seu histórico com licenças de marcas, o tipo e qualidade do produto que ele fabrica, o tipo de distribuição que ele usa para venda e o posicionamento preço dos produtos dele) porque as outras informações eu já tenho pois conheço bem o segmento e os mercados.

O fabricante também conhece muito bem o seu mercado e o segmento de licenças, então assim como eu, eles estão muito bem preparados. Logo, não se destaca uma parte com maiores informações que a outra. Caso aconteça de uma das partes não estar ciente de alguma informação, o que raramente acontece, ai então, aquela que tiver essa informações terá uma pequena vantagem.

11. Antes e durante o processo de negociação, você avalia as forças e fraquezas da marca frente ao fabricante e vice-versa? Por exemplo, necessidades, alternativas, recursos, tempo.

- Sim. Por conhecer o mercado no qual a marca está pretendendo entrar, e por estudar as características do candidato a licença, eu identifico as forças e fraquezas da marca frente ao fabricante e vice-versa. Esses pontos podem ser muito valiosos para barganhar durante uma negociação.

12. Em uma negociação de licença, qual das partes costuma ter maior poder de barganha, a marca ou o fabricante? Quais são os mais frequentes fatores para este maior poder de barganha em uma negociação de licença?

- Essa relação de força é muito simples. Quanto mais a marca é forte e conhecida, maior o seu poder de barganha. Por outro lado, mais o fabricante é 
importante e incontornável (poucos substitutos do nível dele), maior o poder de barganha dele.

Fatores frequentes da marca: Força da marca (Imagem mundial, implantação mundial, estilista conhecido mundialmente, quantidade de lojas exclusivas no mundo, publicidade e sucesso de venda das linhas da marca)

Fatores frequentes do fabricante: Qualidade do fabricante (produto, distribuição, posicionamento preço).

13. Quais são os aspectos principais e secundários em uma negociação de licença com fabricantes latino americanos? Por exemplo: preços, prazos, direitos, comunicação, ect.

- Aspectos principais: Território, Produtos ou linha a serem licenciados, taxa de royalty, mínimos contratuais anuais, canais de distribuição, tempo de vigência do contrato e o percentual sobre as vendas liquidas anuais de obrigação de despesa em publicidade e promoção.

Aspectos secundários: O prazo para pagamento dos mínimos contratuais ( geralmente são pagos trimestralmente, mas caso o licenciado insistir para pagamento semestral, tudo bem).

14. Antes da negociação, são estabelecidos internamente limites mínimos de rentabilidade ou produção para que a parceria seja interessante para a marca?

- Em uma negociação de licença, são determinados mínimos anuais a serem pagos sob forma de royalties.

Cada caso é um caso. Tem casos, que até por um mínimo elevado, o candidato não interessa. E casos, que a parceria é aceitável até mesmo sem nenhum mínimo.

Para o primeiro caso, onde mesmo com mínimos elevados a parceria não é interessante, o mais frequente é que a qualidade do produto do fabricante seja ruim, pois assim ele estaria enfraquecendo a imagem da marca. Assim como a qualidade do produto, o segmento de distribuição também é um ponto crucial nesta avaliação (também visando preservar a imagem da marca). Na mesma linha de raciocínio, os contratos que não apresentam nenhum mínimo são aqueles em que o fabricante tem uma qualideda de produto e distribuição tão 
fortes que é assumido que a porcentagem a ser paga será maior que qualquer mínimo que eles possam estabelecer.

15. Você dispõe de propostas alternativas em uma negociação de licença com fabricantes para em caso de sua proposta inicial não seja aceita?

- Caso minha proposta inicial não for aceita, minha resposta vai depender das circunstâncias da negociação.

Antes da negociação, eu defino margens de negociação para cada ponto a ser negociado. Cada negociação de licença tem uma imensa variedade de características, dependendo da marca, fabricante, mercado, ect. Tendo essas características em mente, defino as margens na qual a negociação continua sendo vantajosa para os interesses da marca, aos quais eu defendo, e então formulo minha segunda proposta.

16. Antes da negociação, você define quais informações serão prestadas para a outra parte? Você procura manter algumas informações em sigilo? Quais?

- Eu geralmente forneço todas as informações relativas à marca.

Excepcionalmente, pode ter uma informação que eu não divulgue por ela ser irrelevante ou que poderia comprometer o interesse do candidato pela licença, por exemplo: Caso a marca esteja no processo de ser colocada a venda. Neste caso, o fabricante apenas saberia desta informação se a venda for efetivamente realizada.

17. Antes da negociação, você define quais informações pretende obter da outra parte?

- Sim.

1- Qualidade do produto fabricado via envio de amostras ao Studio da marca.

2- vendas realizadas anualmente nos últimos três anos pelo candidato e segmentação por linhas fabricadas.

3- Por linha fabricada, segmento atingido da distribuição.

4- Posicionamento preço ao público. 
18. Você utiliza técnicas de persuasão durante negociações de licenças? Por exemplo: Influenciar o pensamento da outra parte ou induzi-la a determinadas escolhas.

- Não. Não uso técnicas de persuasão, é na força da marca que o interesse deve estar.

19. Quais são os principais aspectos positivos e negativos de se licenciar?

- Os aspectos positivos de licenciar são: A geração de royalty, que podem ser de valor elevado, sem contrapartida de gastos elevados para a marca ea entrada em um novo mercado.

Negativos: Não tem um controle muito forte da homogeneidade das linhas licenciadas nos vários mercados, e tão pouco consegue uma coerência muito grande na distribuição.

\section{Quais são as principais vantagens competitivas da marca ao} fabricar e distribuir sob licença em países latino americanos?

- Frente aos concorrentes nacionais, a maior vantagem competitiva é a atratividade de uma marca internacional.

Frente aos concorrentes nacionais e internacionais, as principais vantagens competitivas são: $O$ posicionamento da marca; a imagem desenvolvida e a notoriedade da marca.

\section{Parte 3}

21. Na sua opinião, essas negociações funcionam melhor se forem feitas presencialmente? 0 uso de aplicativos como Skype têm a mesma eficiência?

- Uma licença sendo normalmente uma relação duradoura, é fundamental criar desde a negociação uma relação transparente, com o melhor entendimento pessoal possível entre as partes. Para isto, o ideal são reuniões presenciais, onde as partes podem criar uma relação profissional e pessoal. Meios de comunicação como Skype, telefone e e-mail também são muito importantes, pois 
se trata de negociações entre diferentes países, o que torna encontros físicos nem sempre viáveis. Reuniões presenciais são a base para uma boa negociação e os outros meios são complementares.

\section{Após o termino de negociações envolvendo a Yves Saint Laurent e fabricantes latino americanos, como é a relação entre estas empresas ao longo da vigência do contrato?}

- É uma relação habitualmente muito cordial e pessoal. Uma vez por ano, um ou mais representantes técnicos da YSL visitam o fabricante, sempre acompanhados pelo responsável da Fashion Licensing. Neste momento, as fábricas são visitadas, os produtos são examinados, são feitas reuniões com estilistas do fabricante, são conversados os problemas encontrados na exploração da licença e no mercado, além de visitas nos pontos de venda. Um representante do fabricante também visita anualmente YSL em Paris. Esta visita se concentra unicamente em reuniões para aprovação de coleção. Além destas visitas, sempre que necessário, as empresas se comunicam via e-mail, telefone ou Skype. Todo esse contato entre a YSL e seus fabricantes licenciados quase sempre demonstra uma relação positiva, de trabalho e acompanhamento da licença. Os contratos são muito raramente rescindidos de maneira antecipada, e quase sempre são renovados.

\section{Após o termino de negociações envolvendo a Vila Romana e marcas europeias, como é a relação entre estas empresas ao longo da vigência do contrato?}

Assim como a YSL, a Vila Romana também sempre demonstrou o melhor relacionamento possível com as marcas. Muito dificilmente conflitos ocorrem e a relação predominante é de harmonia e longo prazo. Os contratos também costumam ser renovados e as rescisões são muito excepcionais. 


\section{Anexo 2}

\section{Entrevista - Fabricante \\ Sr. Carlos Isaac - Presidente da Vila Romana}

1. Em uma negociação de licença com marcas europeias, você evita conflitos com a outra parte ou encara qualquer tipo de situação para ter êxito na sua vontade?

- Eu sempre evito conflitos. Porém, se houver no contrato uma ou várias clausulas que podem ser prejudiciais para a minha empresa ou a uma boa exploração da licença, negocio essas clausulas. Caso não tiver um resultado satisfatório na negociação destas clausulas, então a licença em questão não é do interesse da minha empresa e a negociação não segue adiante.

2. Você diria que a experiência que você acumulou ao longo da vida, seja pessoal, acadêmica ou profissional, ajuda nas suas negociações? De que maneira?

- Ajuda muito. De todas as maneiras.

3. Antes de uma negociação com marcas representadas pela Fashion Licensing, você faz um repertório para prever as possíveis reinvindicações de seus interlocutores, afim de ter as melhores respostas/propostas para ambas as parte?

- Os pontos abordados em uma negociação licença são sempre os mesmos. Deste modo, eu já sei quais são as propostas que posso ou não aceitar para cada um destes pontos, seja para porcentagem de royalties, território ou qualquer outro. Frente a reivindicação de meus interlocutores, caso seja algo que eu não aceite visando preservar os interesses da minha empresa, como já tenho experiência em licenças e conheço bem cada tópico abordado, já sei automaticamente a minha resposta e proposta para a outra parte. 
4. Antes de uma negociação, você procura se munir de todas as informações referentes ao assunto? Você percebe uma vantagem na negociação para o lado que tem mais informações sobre o assunto?

- Sim. Me informo sobre a imagem da marca e sua notoriedade, tanto no exterior como no Brasil como no exterior, me informo sobre a receptividade potencial da marca no mercado e sobre a rede de lojas multimarcas. Verifico que a marca não tenha sido mal explorada anteriormente no mercado nacional.

Existe uma vantagem clara para o lado com mais informações.

5. Durante o processo de negociação, você avalia suas forças e suas fraquezas frente a outra parte? Por exemplo, necessidades, alternativas, recursos, tempo, ect.

- Eu não diria que eu avalio as forças e as fraquezas propriamente ditas. O que eu avalio, e que neste caso é equivalente a uma força ou uma fraqueza, é o meu grau de interesse pela marca. Quanto maior meu interesse, mais tende para uma fraqueza da minha parte. Do mesmo modo, quanto menor meu interesse, mais tende para uma força da minha parte durante o processo de negociação, pois não tenho assim uma necessidade tão grande pela licença.

6. Em sua opinião, em uma negociação de licença, qual das partes costuma ter maior poder de barganha, a marca ou o fabricante? Quais são os fatores mais frequentes para este maior poder de barganha em uma negociação de licença?

- O poder de barganha também é diretamente relacionado ao interesse que eu tenho pela marca e vice-versa. O aspecto que influencia esse interesse é o grau de notoriedade da marca. Quanto maior este grau, maior o poder de barganha da marca, e por consequência, quanto menor este grau for, maior o meu poder de barganha. Como eu negocio com marcas com alto e com baixo grau de notoriedade, não existe uma tendência de que parte tem maior poder de barganha. 
7. Quais são os aspectos principais e secundários em uma negociação de licença com marcas europeias? Por exemplo: preços, prazos, direitos, comunicação, ect.

- Cada aspecto da negociação é parte de um todo.

Principais: Taxa de Royalty, mínimos contratuais, Produtos licenciados, assistência técnica (produto e publicidade).

Secundários: Prazos de pagamentos.

8. Antes da negociação, são estabelecidos internamente limites máximos e mínimos de rentabilidade ou produção para que a parceria seja interessante?

- Antes da negociação de uma licença, eu faço uma projeção de vendas com esta marca no meu mercado. Caso essa projeção não corresponda a um volume interessante para minha empresa, a parceria não é interessante.

9. Você dispõe de propostas alternativas em uma negociação de licença com marcas representadas pela Fashion Licensing para em caso de sua proposta inicial não ser aceita?

- Eu não disponho de outras propostas. Eu vou apresentar a minha proposta inicial. Caso algum dos pontos não seja aceito pela outra parte, eu vou tentar torná-lo mais interessante para a marca. A minha flexibilidade nesta melhoria da proposta será definida pelo meu grau interesse pela licença da marca.

10. Antes da negociação, você define quais informações serão prestadas para a outra parte? Você procura manter algumas informações em sigilo? Quais?

- Em geral, eu procuro ser o mais transparente possível em uma negociação de licença de marca. No entanto, considero certos dados confidenciais, como as vendas que realizamos com outras grifes licenciadas e as clausulas contratuais que temos com essas grifes. 
11. Antes da negociação, você define quais informações pretende obter da outra parte?

- Sim. As informações que eu geralmente procuro obter são: A localização de lojas, volume de vendas, detalhes da assistência técnica prestada ao licenciado a nível de produto, publicidade, merchandising e conceitos corner e boutique.

12. Você utiliza técnicas de persuasão durante negociações de licenças? Por exemplo: Influenciar o pensamento da outra parte ou induzi-la a determinadas escolhas.

- Através da argumentação, procuro mostrar para meus interlocutores os fundamentos da minha posição e convencê-los de que a minha proposta é a melhor possível para ambas as partes.

13. Quais são as principais vantagens competitivas de se fabricar e distribuir uma marca europeia sob licença?

- A principal vantagem é se diferenciar frentes as marcas nacionais, se beneficiando da imagem mundial e do reconhecimento da marca europeia junto ao público. 


\section{Anexo 3}

\section{Entrevista - Marca}

Sra. Françoise Gauci - Gerente de Licenças da Yves Saint Laurent

1. Em uma negociação de licença com fabricantes latino americanos através da Fashion Licensing, você evita conflitos com a outra parte ou encara qualquer tipo de situação para ter êxito na sua vontade? E em negociações diretas com o fabricante?

- A Fashion Licensing, agindo como nosso representante, sabe quais clausulas não são negociáveis e quais são. Para as que não são negociáveis, caso o fabricante não concorde com uma ou mais delas, então a parceria simplesmente não é efetuada, não havendo conflito. Para as clausulas que são negociáveis, sempre evitamos conflitos procurando soluções que convenham para ambas as partes. Em uma licença, é fundamental um bom entendimento e relação entre a marca e o fabricante, por isso o conflito nunca é do nosso interesse.

2. Você diria que a experiência que você acumulou ao longo da vida, seja pessoal, acadêmica ou profissional, ajuda nas suas negociações? De que maneira?

- A experiência que eu acumulei facilita nas negociações pois os dilemas com os quais me deparo são recorrentes, sendo assim, já conheço as diferentes soluções para os mesmos.

3. Antes de uma negociação com fabricantes trazidos pela Fashion Licensing, você faz um repertório para prever as possíveis reivindicações de seus interlocutores, a fim de ter as melhores respostas/propostas para ambas as parte? 
- O nosso agente se encarrega de negociar todos os pontos e nos apresenta um projeto completo para aprovação, com eventuais renegociações de um ou mais pontos. Mas as possíveis alterações destes pontos serão estudadas apenas após a reivindicação ser feita pelo candidato a licença.

4. Antes de uma negociação, você procura se munir de todas as informações referentes ao assunto? Você percebe uma vantagem na negociação caso um lado tenha mais informações sobre o assunto?

- Antes de elaborar uma proposta, o nosso gente, no caso a Fashion Licensing, nos fornece informações específicas sobre o candidato a licença, bem como a situação atual do mercado na qual este candidato esta inserido. Com essas informações, passamos a conhecer o mercado e o fabricante no qual estamos prestes a investir, desta maneira, sabemos nos posicionar de maneira realística na negociação, exigindo apenas condições viáveis para a outra parte.

5. Durante o processo de negociação, você avalia suas forças e suas fraquezas frente a outra parte? Por exemplo, necessidades, alternativas, recursos, tempo, ect.

- Durante o processo de negociação também, mas esta avaliação é feita principalmente antes da negociação se dar por iniciada. Esta avaliação visa em um primeiro momento analisar se a parceria é ou não do nosso interesse. Em um segundo momento, esta avaliação será usada para basear nossos argumentos ao longo da negociação.

6. Na sua opinião, em uma negociação de licença, qual das partes costuma ter maior poder de barganha, a marca ou o fabricante? Quais são os fatores mais frequentes para este maior poder de barganha em uma negociação de licença?

- Nos não consideramos na negociação o poder de barganha. O que nos interessa é a alta qualidade dos produtos e distribuição de um candidato. Quanto maior sua qualidade, mais estaremos interessados em tê-lo como licenciado. Assim como, quanto mais forte o nome da nossa marca, maior o interesse do candidato em fabricar nossos produtos. No entanto, mesmo tendo um forte nome 
e por consequência um grande poder de barganha, não usaremos esse fator como uma arma durante a negociação para tirar o melhor proveito possível da situação e um negócio mais rentável possível para nossa empresa. Nós entendemos que uma licença tem que ser promissora tanto para nos, como para nosso parceiro fabricante, desta maneira, buscamos chegar a um acordo onde ambas as partes estejam satisfeitas.

7. Quais são os aspectos principais e secundários em uma negociação de licença com fabricantes latino americanos? Por exemplo: preços, prazos, direitos, comunicação, ect.

- Reparamos que os mercados da América Latina são muito pouco integrados. Países vizinhos podem ser muito diferentes quanto ao posicionamento preço, sourcing e o tipo de distribuição. Sendo assim, para cada país com o qual negociamos, precisamos entender a realidade de cada um desses fatores, que nos julgamos serem os mais importantes.

8. Antes da negociação, são estabelecidos internamente limites máximos e mínimos de rentabilidade ou produção para que a parceria seja interessante?

- Em negociações de licenças, estes mínimos são não somente definidos internamente, como também constam em contrato. Caso a porcentagem das vendas liquidas a ser paga pelo licenciado em forma de royalty não alcançar o valor do mínimo contratual, então o valor a ser pago é o mínimo contratual, e não a porcentagem sobre as vendas.

9. Antes da negociação, você define quais informações serão prestadas para a outra parte? Você procura manter algumas informações em sigilo? Quais?

- Somos totalmente transparente em relação a informações referentes a nossa empresa e a comunicação e parte do nosso trabalho. Desta forma, não vejo nenhuma informação específica que procuremos preservar.

10. Antes da negociação, você define quais informações pretende obter da outra parte? 
- Sim. Mesmo antes de procurarmos por estas informações, o nosso agente representante nos as fornece previamente a negociação. Este é o primeiro passo para definirmos se temos ou não interesse em dar inicio negociação. Essas informações consistem essencialmente em financeiras, industriais, de distribuição, de posicionamento imagem e vendas.

11. Você utiliza técnicas de persuasão durante negociações de licenças? Por exemplo: Influenciar o pensamento da outra parte ou induzi-la a determinadas escolhas.

- Talvez inconscientemente, mas conscientemente acho que não.

\section{Quais medidas você adota para garantir os direitos de propriedade} da marca? Essas medidas apresentam baixo, médio ou alto custo?

- A nossa marca e nosso logotipo são registrados legalmente nas classes de nossa atividade em todos os países em que atuamos assim como outros. $O$ registro é feito por marca por país e o valor é em média de 1000 dólares. Caso o registro seja feito em mais de um país, o valor de multiplica pelo número de países, podendo ser um pouco mais ou um pouco menos dependendo do país.

13. Quais são as principais vantagens competitivas da marca ao fabricar e distribuir sob licença em países latino americanos?

- Com o alto custo da importação, o preço ao público dos produtos importados fica muito elevado, o que resulta em baixos níveis de venda. Com o sistema de licença, nos evitamos esse alto custo, o que possibilita um preço ao público muito competitivo.

Frente às linhas nacionais, nos apresentamos a vantagem de sermos uma marca internacional com forte criatividade. 